Atmos. Chem. Phys., 17, 15095-15119, 2017

https://doi.org/10.5194/acp-17-15095-2017

(c) Author(s) 2017. This work is distributed under

the Creative Commons Attribution 4.0 License.

\title{
Characterizing energy budget variability at a Sahelian site: a test of NWP model behaviour
}

\author{
Anna Mackie ${ }^{1}$, Paul I. Palmer ${ }^{1,2}$, and Helen Brindley ${ }^{3}$ \\ ${ }^{1}$ School of GeoSciences, The University of Edinburgh, Edinburgh, UK \\ ${ }^{2}$ National Centre for Earth Observation, The University of Edinburgh, Edinburgh, UK \\ ${ }^{3}$ National Centre for Earth Observation, Imperial College London, London, UK
}

Correspondence: Anna Mackie (anna.mackie@ed.ac.uk)

Received: 15 June 2017 - Discussion started: 30 August 2017

Revised: 27 October 2017 - Accepted: 4 November 2017 - Published: 21 December 2017

\begin{abstract}
We use observations of surface and top-of-theatmosphere (TOA) broadband radiation fluxes determined from the Atmospheric Radiation Measurement programme mobile facility, the Geostationary Earth Radiation Budget (GERB) and Spinning Enhanced Visible and Infrared Imager (SEVIRI) instruments and a range of meteorological variables at a site in the Sahel to test the ability of the ECMWF Integrated Forecasting System cycle 43r1 to describe energy budget variability. The model has daily average biases of -12 and $18 \mathrm{~W} \mathrm{~m}^{-2}$ for outgoing longwave and reflected shortwave TOA radiation fluxes, respectively. At the surface, the daily average bias is $12(13) \mathrm{W} \mathrm{m}^{-2}$ for the longwave downwelling (upwelling) radiation flux and $-21(-13) \mathrm{W} \mathrm{m}^{-2}$ for the shortwave downwelling (upwelling) radiation flux. Using multivariate linear models of observation-model differences, we attribute radiation flux discrepancies to physical processes, and link surface and TOA fluxes. We find that model biases in surface radiation fluxes are mainly due to a low bias in ice water path (IWP), poor description of surface albedo and model-observation differences in surface temperature. We also attribute observed discrepancies in the radiation fluxes, particularly during the dry season, to the misrepresentation of aerosol fields in the model from use of a climatology instead of a dynamic approach. At the TOA, the low IWP impacts the amount of reflected shortwave radiation while biases in outgoing longwave radiation are additionally coupled to discrepancies in the surface upwelling longwave flux and atmospheric humidity.
\end{abstract}

\section{Introduction}

The balance at the top of the atmosphere (TOA) between solar and thermal radiation fluxes determines the energy budget of the climate system. A proportion of the incoming solar radiation is reflected back into space, but the majority is absorbed by the Earth and its atmosphere which subsequently emit radiation at longer wavelengths. At the TOA, there are three broadband radiation components: (1) incoming solar (often referred to as total solar irradiance - TSI); (2) outgoing reflected solar (or reflected shortwave radiation - RSR); and (3) thermal outgoing (or outgoing longwave radiation OLR). To be able to confidently describe future changes in climate, climate models must be able to produce a realistic representation of this TOA radiation budget and have some skill at simulating past states that can be evaluated using data (Flato et al., 2013). Here, we use surface and TOA radiation flux measurements to test the model skill of a numerical weather prediction (NWP) model, the ECMWF Integrated Forecasting System (IFS).

Our understanding of the TOA radiation budget has been vastly improved by dedicated satellite missions (e.g. Hartmann et al., 2013; Brindley and Bantges, 2016). These instruments typically have the advantage of global spatial coverage over multi-year temporal coverage, making them ideal for studying a wide spectrum of TOA flux variations (Wielicki et al., 2002; Wild, 2009; Loeb et al., 2012) and evaluating climate models (Milton et al., 2008; Miller et al., 2012; Dolinar et al., 2015). In this study, we use TOA broadband radiation fluxes determined from the Geostationary Earth Radiation Budget (GERB) and Spinning Enhanced Visible and Infrared 
Imager (SEVIRI) instruments (Schmetz et al., 2002; Harries et al., 2005). Although these instruments do not have global coverage they have the advantage of high $(15 \mathrm{~min})$ temporal resolution.

TOA radiation fluxes are determined by processes at the surface and throughout the atmosphere. Measurements of surface radiation fluxes are therefore helpful in modelling radiative processes. Surface measurements are generally much sparser than satellite data, though some surface networks exist, such as the Baseline Surface Radiation Network (BSRN; Ohmura et al., 1998) and the Atmospheric Radiation Measurement (ARM) programme. The ARM programme includes three permanent sites and three ARM mobile facilities (AMFs), which are deployed in different geographical locations. Here, we use data from an AMF deployment in Niamey, Niger, during 2006 (Miller and Slingo, 2007). Data collected during this campaign consist of not only highfrequency surface radiation measurements but also coincident measurements of atmospheric variables relevant to the study of radiation transfer, including aerosol optical depth, atmospheric humidity, $2 \mathrm{~m}$ air temperature and data from sonde ascents.

We use surface and TOA radiation flux measurements over Niamey to evaluate the performance of the IFS cycle 43r1 from the European Centre for Medium-Range Weather Forecasts (ECMWF), a subsequent cycle to cycle $31 \mathrm{r} 2$ on which the ERA-Interim reanalysis is based. Using the model helps us to link observed radiation flux variations at the surface to TOA radiation fluxes and to quantify the influence of radiative and non-radiative variables on model error.

The combination of data available from the AMF and GERB/SEVIRI provides valuable insight into radiative processes in a region where surface measurements are scarce. In particular, the high temporal frequency of the data allows us to look in detail at the relationships and dependencies between key variables. It is worth noting that although this study is necessarily limited to the one measurement site at Niamey, this location was chosen carefully in order to sample the range of climatic conditions typically experienced across the wider Sahelian region (Miller and Slingo, 2007).

In the next section, we describe the study site at Niamey, Niger, and the associated key components of radiative transfer. We present the data and methods in Sect. 3. In Sect. 4, we present our analysis of individual components of the radiation flux, including an analysis of the model error. We provide conclusions in Sect. 5.

\section{Description of the Niamey study region}

Niamey, Niger $\left(13^{\circ} 29^{\prime} \mathrm{N}, 2^{\circ} 11^{\prime} \mathrm{E}\right)$, was selected for the first AMF deployment because the characteristic climatology of the location exhibits strong variability that substantially affects the corresponding behaviour of the TOA and surface radiative fluxes. Regional dust storms and biomass burn- ing plumes significantly impact the energy budget (Slingo et al., 2006; McFarlane et al., 2007), with dry season aerosol loading composed of varying proportions of mineral dust and biomass burning aerosol from agricultural fires (Johnson et al., 2008). Additionally, the annual progression of the Intertropical Front (ITF) drives the west African monsoon (WAM) and imposes a strong seasonal cycle on radiation fluxes due to the onset of the wet season from approximately April to October (Slingo et al., 2008).

The AMF deployment over Niamey was from late 2005 to early 2007. It included measurements of a range of meteorological, thermodynamic and radiative variables. The deployment was designed to coincide with the availability of TOA broadband radiation fluxes from GERB. Data from AMF and GERB could then be reconciled to identify problems in radiative transfer schemes and numerical weather prediction (Miller and Slingo, 2007).

\subsection{Overview of radiation and meteorological environments}

Figure 1 is used to present the key features of radiative transfer of the Earth-atmosphere system, with the following section outlining key aspects of this in Niamey. We refer the reader elsewhere for further, in-depth details (e.g. Slingo et al., 2008, 2009).

The incident solar radiation (TSI) enters the top of the atmosphere. A fraction of the TSI is transmitted through the atmosphere, reaching the surface as "direct" solar radiation (Fig. 1, arrow 1d). When water vapour (arrow 1a), cloud (arrow 1b) or aerosol (arrow 1c) is present, a significant fraction of the incident solar beam will be absorbed or scattered. Some of the scattered radiation will be scattered down to the surface as "diffuse" solar radiation (arrows 2a, 2b, 2c). The combination of the diffuse and direct downward radiation combine to form the total downwelling solar, or shortwave, radiation at the surface (DSR; labelled 2 in Fig. 1). A fraction of this downwelling solar radiation will be reflected, determined by the surface albedo, as upwelling shortwave radiation (USR; labelled 3). The fraction of the USR that is transmitted up through the atmosphere, combined with the solar radiation scattered upwards by atmospheric molecules, clouds and aerosol and escaping to space (arrows $4 \mathrm{a}, 4 \mathrm{~b}$ ), represents the reflected solar radiation at the TOA (RSR; labelled 4).

Longwave radiation fluxes also depend on the meteorological conditions. Resulting thermal emissions from the surface (upwelling longwave radiation - ULR; labelled 5) can be absorbed by atmospheric molecules (predominantly water vapour; arrow 5), clouds (arrow 5b) and dust aerosol (arrow $5 c)$ depending on the season. Subsequent emission of radiation from these absorbers contributes to the downwelling longwave radiation at the surface (DLR; arrows $6 a, 6 b, 6 c$ ) and outgoing longwave radiation (OLR; arrows 7a, 7b, 7c) at the TOA. The OLR also includes the fraction of radiation 


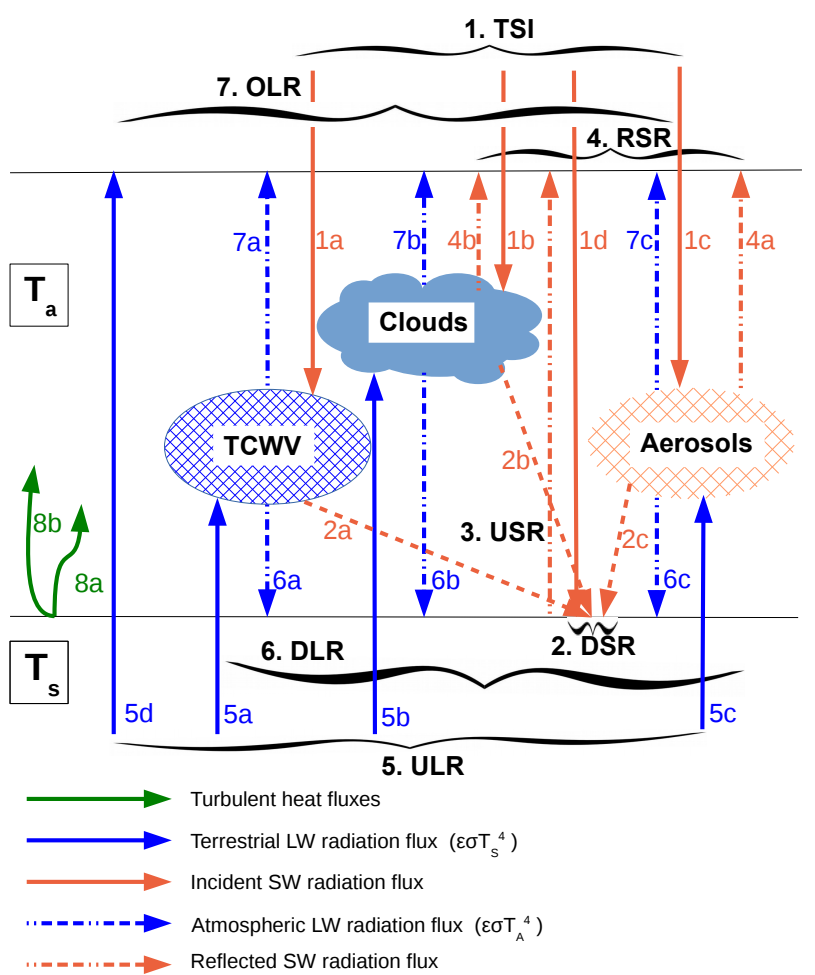

Figure 1. Simplified schematic of major processes controlling broadband radiation fluxes. Red arrows indicate shortwave radiation fluxes; blue arrows longwave radiation fluxes. For a detailed description of the arrows, please see Sect. 2.1.

emitted by the surface that is transmitted through the atmosphere and escapes directly to space (arrow $5 \mathrm{~d}$ ). The surface also cools by sensible heat flux (SHF; arrow 8a) or, depending on soil moisture content, latent heat flux (LHF; arrow $8 b)$.

There are distinct dry and wet seasons in Niamey, determined by the position of the surface ITF, the boundary between the moist air coming from the southwest from tropical Atlantic and the warmer, dry air coming from the northeast from the Sahara (Hasternath and Lamb, 1977; Lélé and Lamb, 2010). During 2006, the first dry season ran from days 1 to 125 , the wet season from days 126 to 300 and the second dry season from days 301 to 365 , as determined by a sustained dew point temperature of at least $15^{\circ} \mathrm{C}$ (Slingo et al., 2008). Figure 2 shows that during the first dry season, given clear conditions, there is a steady increase in surface DSR as the year progresses. Dry conditions will typically lead to a relatively constant surface albedo such that RSR and USR (Fig. 2a and c) also increase with time. Figure 3 implies that the increasing DSR results in surface warming, which in turn leads to enhanced ULR. The presence of clouds, water vapour and aerosols leads to deviations from this trend. Aerosols from dust storms, blown in from the Sahara, decrease DSR (McFarlane et al., 2009), enhance DLR (Miller et al., 2009) and increase RSR. Periodic increases in cloudi- ness and total column water vapour (TCWV) can lead to increased absorption of both long- and shortwave radiation. This results in decreases in DSR, increases in RSR and increases in DLR due to atmospheric warming.

After the northwards passing of the ITF over Niamey in April, Niamey enters the wet season. The further northward the ITF migrates, the greater the vertical extent of the moist air mass above Niamey. TCWV therefore peaks when the ITF is at its most northerly, leading to a period with deep convective clouds and increased precipitation (Lélé and Lamb, 2010). Greater cloud cover leads to enhanced shortwave (SW) reflection back to space and atmospheric SW radiative heating which reduce the DSR. Clouds and increased TCWV also absorb in the longwave (LW), reducing OLR and enhancing DLR (Fig. 3). Decreases in DSR reduce the shortwave radiative heating of the surface, therefore decreasing ULR. Increases in precipitation, and therefore higher soil moisture, affect the partition between radiative, sensible and latent heating.

\subsection{Overview of previous studies}

There are a number of studies that have evaluated radiative processes in west Africa as represented by various models, which point to the difficulties in simulating the processes which control radiative transfer in the Sahel. Miller et al. (2012) examine the impact of hydrological variables on broadband atmospheric column divergence in Niamey using both the data from the AMF/GERB and output from four global climate models (GCMs). They show that the reasonably well-modelled net broadband divergence across the atmosphere is the product of error cancellation of longwave and shortwave divergences. GCMs such as these are not intended to exactly replicate the exact state of the atmosphere but rather capture long-term spatial and temporal patterns. Operational forecasts and reanalyses, however, assimilate observational data regularly and aim to simulate the atmosphere as closely as possible. As Walsh et al. (2009) discuss, high temporal frequency observations at specific points are ideal for comparison to reanalyses: not only do observational constraints make the projections as realistic as possible, but reanalyses often share aspects with GCMs which means evaluating them can simultaneously improve our understanding of underlying models used to make climate predictions.

There has also been some comparison of operational forecasts to data from the AMF and GERB at Niamey during 2006. Agustí-Panareda et al. (2010), in their wider comparison of west African data to ECMWF's operational forecast, briefly look at how well surface broadband fluxes are modelled in Niamey. They note that there are periods in the dry season where the observed DSR decreases which are not present in the model and attribute this primarily to the use of a constant climatology for aerosol loading and missing cloudy conditions. ERA-I has also been evaluated by other studies in west Africa (Marsham et al., 2015), which find 

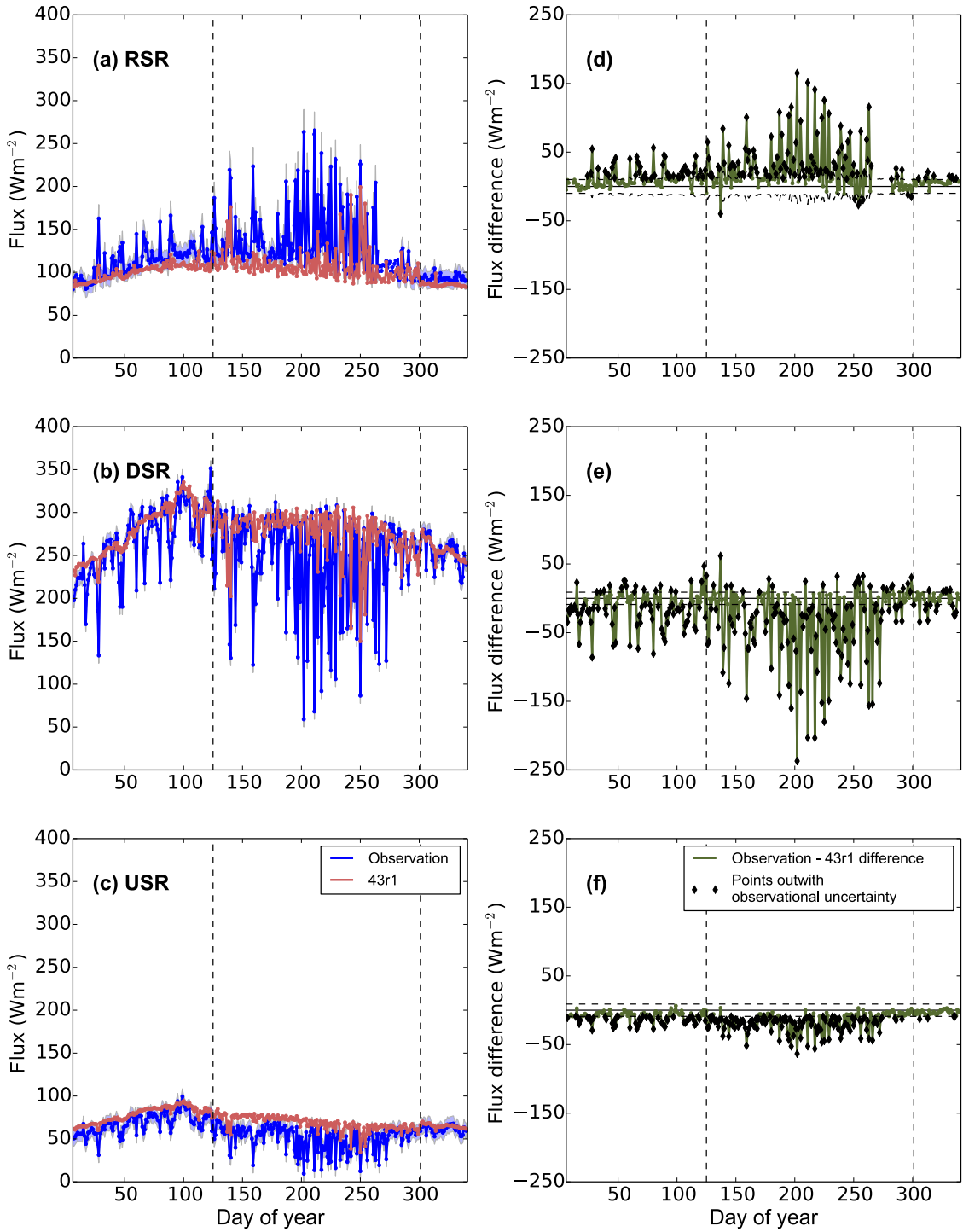

Figure 2. Daily means of observed (blue, from AMF and GERB) and 43r1 (red) shortwave radiation fluxes at Niamey during 2006. Lines become dashed when values are from interpolation (see Sect. 3). Plots show observed and 43r1 (a) TOA reflected shortwave; (b) surface downwelling shortwave; (c) surface upwelling shortwave radiation fluxes; and the observation-43r1 difference of these same fluxes in plots (d)-(f), respectively. Black diamonds on plots (d)-(f) indicate model values outside of the observational uncertainty range (horizontal dashed lines). Vertical dashed lines indicate the beginning and end of the wet season.

that TCWV is well captured by the model and that its role in controlling TOA net flux is more important than that of dust.

\section{Data and methods}

\subsection{Data and their uncertainties}

We use GERB-like high-resolution TOA broadband radiation fluxes, hereinafter referred to as GERB fluxes, with a temporal resolution of $15 \mathrm{~min}$ and a spatial resolution of $10 \mathrm{~km}$ at nadir (Dewitte et al., 2008). This product uses SEVIRI mea- surements, passed through the GERB processing algorithms, to derive broadband fluxes throughout the year.

Table 1 summarizes the surface radiative and non-radiative variables that we use from the AMF during 2006. Direct, diffuse and total shortwave fluxes were measured using a normal incidence pyrheliometer, and shaded and unshaded pyranometers, respectively, while longwave fluxes were measured using shaded and unshaded pyrgeometers. These were complemented with inferences of turbulent heat fluxes (THFs) from an eddy correlation system. From the ARM-standard meteorological instruments, we use $2 \mathrm{~m}$ air temperature. The temperature and pressure measurements at 

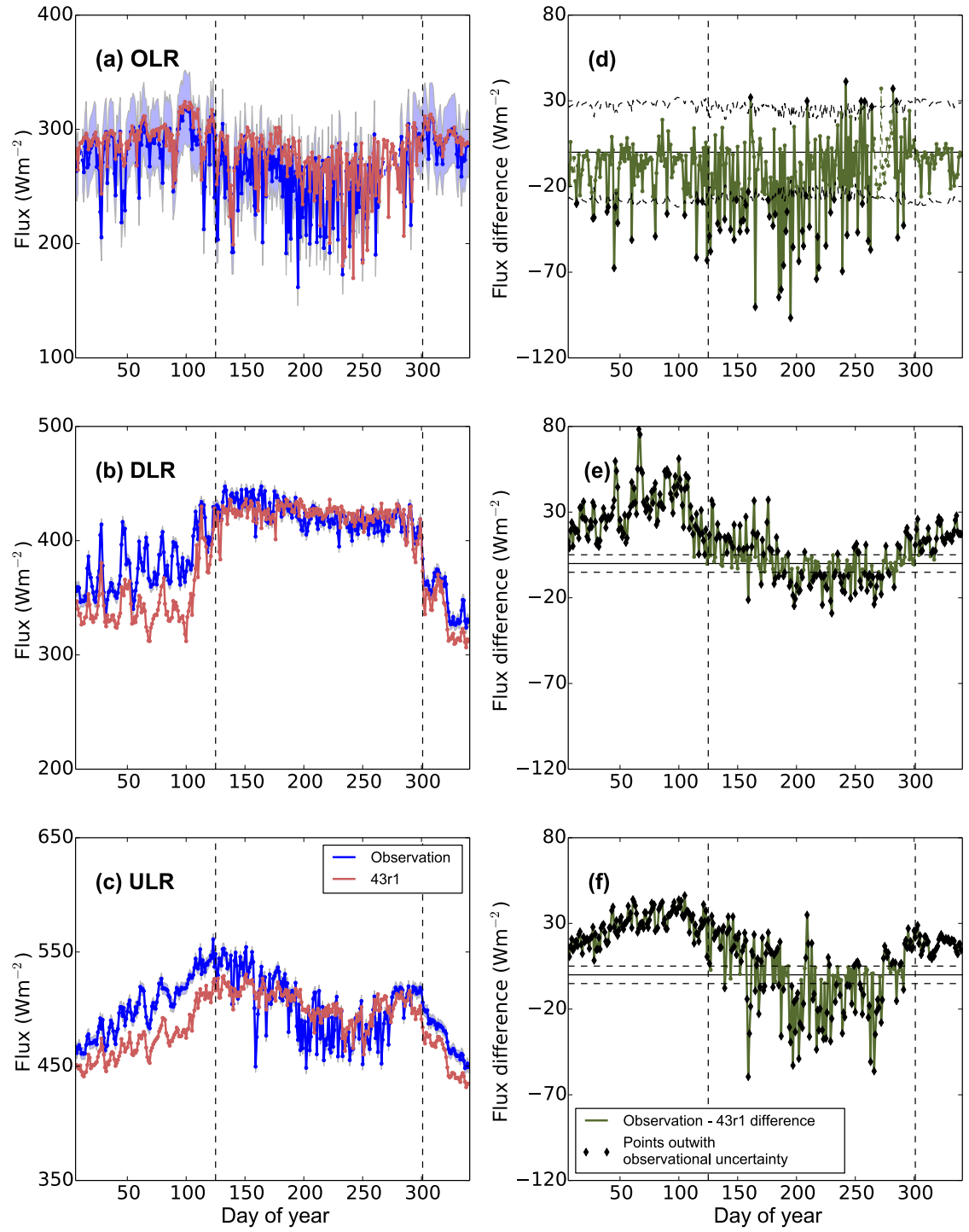

Figure 3. The same as Fig. 2 but for longwave fluxes. Plots show observed and 43r1 (a) TOA outgoing longwave; (b) surface downwelling longwave; (c) surface upwelling longwave radiation fluxes; and the observation-43r1 difference of these same fluxes in plots (d)-(f), respectively.

altitude, required for TCWV estimates, come from Vaisala RS-92 radiosonde ascents. We also use relative humidity (RH) profiles from the sonde ascents to extract upper tropospheric humidity (UTH), defined, following Brindley (2007), as the average RH between 500 and $200 \mathrm{hPa}$. Finally, we use aerosol optical depth (AOD) at $500 \mathrm{~nm}$ from the multiplefrequency rotating shadow band radiometer (MFRSR), corrected for forward scattering (Harrison et al., 1994; Michalsky et al., 2001). In addition to these surface-based measurements, we use ice water path (IWP) and liquid water path (LWP) daily averages derived from SEVIRI provided by the Climate Monitoring Satellite Application Facility (CMSAF, Finkensieper et al. (2016)).
When comparing AMF and GERB data, we consider two sources of error associated with (1) the determination of the quantities being measured by an instrument and (2) relating a point AMF measurement with a GERB flux measurement that is representative of a much larger spatial scale (Settle et al., 2008). Slingo et al. (2009) estimate uncertainties in GERB fluxes to be approximately 5 and $10 \mathrm{~W} \mathrm{~m}^{-2}$ for the short- and longwave, respectively. However, Ansell et al. (2014) argue that this underestimates the uncertainty and estimate the instantaneous flux uncertainty to be $10 \%$ for both long- and shortwave fluxes. In this study, we use whichever of these is larger on a particular day, along with the AMF uncertainties of 5 and $9 \mathrm{~W} \mathrm{~m}^{-2}$ for surface long-and shortwave fluxes following Slingo et al. (2009). Uncertainties in other 
Table 1. Radiative and non-radiative data used from the AMF, with dates for which the data stream is available in 2006. Data are available from the ARM archive: http://www.archive.arm.gov.

\begin{tabular}{|c|c|c|c|c|c|}
\hline Variable & Data stream & Description & Frequency & Period (2006-mm-dd) & Uncertainty \\
\hline $\begin{array}{l}\text { Shortwave radiation } \\
\text { flux }\left(\mathrm{W} \mathrm{m}^{-2}\right)\end{array}$ & qcrad1longM1.s2 & $\begin{array}{l}\text { Up- and downwelling, at sur- } \\
\text { face }\end{array}$ & 1 min avg & $01-01-12-31$ & $9 \mathrm{~W} \mathrm{~m}^{-2}$ \\
\hline $\begin{array}{l}\text { Longwave radiation } \\
\text { flux }\left(\mathrm{W} \mathrm{m}^{-2}\right)\end{array}$ & qcrad1longM1.s2 & $\begin{array}{l}\text { Up- and downwelling, at sur- } \\
\text { face }\end{array}$ & $1 \mathrm{~min}$ avg & $01-01-12-31$ & $5 \mathrm{~W} \mathrm{~m}^{-2}$ \\
\hline Temperature $\left({ }^{\circ} \mathrm{C}\right)$ & nimmetM1.b1 & Temperature, air, at $2 \mathrm{~m}$ height & $1 \mathrm{~min}$ avg & 01-01-12-08 & $1 \%$ \\
\hline TCWV $(\mathrm{cm})$ & nimsondewnpnM1.b1 & $\begin{array}{l}\text { Temperature, dew point, } \\
\text { at altitude } \\
\text { Pressure, atmospheric, } \\
\text { at altitude }\end{array}$ & $6 \mathrm{~h}$ & $01-06-12-31$ & $\begin{array}{l}0.5^{\circ} \mathrm{C} \\
1 \mathrm{hPa}\end{array}$ \\
\hline $\begin{array}{l}\text { Turbulent fluxes } \\
\left(\mathrm{W} \mathrm{m}^{-2}\right)\end{array}$ & nim30qcecorM1.s1 & $\begin{array}{l}\text { Latent heat flux } \\
\text { Sensible heat flux }\end{array}$ & $30 \mathrm{~min}$ avg & 01-01-12-31 & $6 \%$ \\
\hline Aerosol optical depth & AOD-FLYNN & $\begin{array}{l}\text { AOD at } 500 \mathrm{~nm} \text { derived from } \\
\text { MFRSR corrected }\end{array}$ & 1-day avg & $01-01-12-31$ & 0.005 \\
\hline
\end{tabular}

AMF variables are given in Table 1, while those in IWP and LWP are provided by CMSAF and have an annual mean of 0.021 and $0.015 \mathrm{~kg} \mathrm{~m}^{-2}$, respectively.

For ease of comparison, all data are processed into daily means. Figures 2, 3 and 4 show daily means of shortwave and longwave fluxes, and non-radiative variables, respectively. For our analysis, as described below, we use continuous data sets that are regularly spaced in time. We use the period 7 January- 8 December, determined by the availability of sonde and air temperature data, and impute missing values. Missing values from the AMF data are imputed using a linear interpolation. We also use a linear interpolation for missing GERB data points for gaps of one data point; otherwise, we use a climatology from 2005 to 2014. In the majority of cases, this corresponds to a 9-year mean.

\subsection{Model and data analysis}

We compare the daily means of the radiation and meteorological variables to corresponding model output from IFS cycle 43r1 (Fig. 4). We use the Tco399 resolution of IFS cycle $43 \mathrm{r} 1$, with a global horizontal resolution of approximately $29 \mathrm{~km}$ and 137 vertical levels. The radiation scheme is called every hour, with approximate updates every model time step (15 min) using the approach of Hogan and Bozzo (2015). Both cycle 43r1 and ERA-I use a climatological aerosol distribution (Dee et al., 2011), derived from Tegen et al. (1997).

To evaluate the daily mean model radiative and nonradiative variables, we use the square of Pearson's correlation coefficient $\left(r^{2}\right)$, which we assume is statistically significant only if the $p$ value $<0.001$, and the root mean square error (RMSE). We also use the average daily model bias, which we define as

bias $=\frac{\sum_{i}^{n}\left(x_{i}^{O}-x_{i}^{M}\right)}{n}$,

where $x_{i}$ is the variable in question on day $i, n$ denotes the number of days and the superscripts $O$ and $M$ denote observation and model, respectively.

We use multivariate models to link observed and model variables. To build the multivariate linear models for a particular variable, we identify potential predictor variables based on the schematic in Fig. 1 to give a physical rationale for selection. There are two requirements for the predictor variable to be included in the linear model to avoid overfitting: first, the predictor variables must have a statistically significant correlation with the dependent variable which also tests whether the linear approximation is appropriate; second, the predictor variables must be independent of each other (Wilks, 2011). To achieve this, we first perform a least-squares regression of the predictor variable on the dependent variable and then between the selected predictor variables to ensure mutual independence.

We select predictor variables according to the criteria above in order to build linear models of the observed and 43r1 fluxes. This has two purposes: not only does this highlight the relative importance of different predictor variables in both the observations and 43r1, but it also indicates generally how well a linear multivariate model is able to capture the variability. Finally, we build models of the differences between observed and 43r1 variables: we define the observed$43 \mathrm{r} 1$ value to be the "discrepancy". The uncertainties in the linear models are derived from the measurement uncertainties, propagated with the uncertainty from the linear model. We evaluate model performance by assessing the variation in the discrepancy which is explained by the linear model using the $r^{2}$ value. 


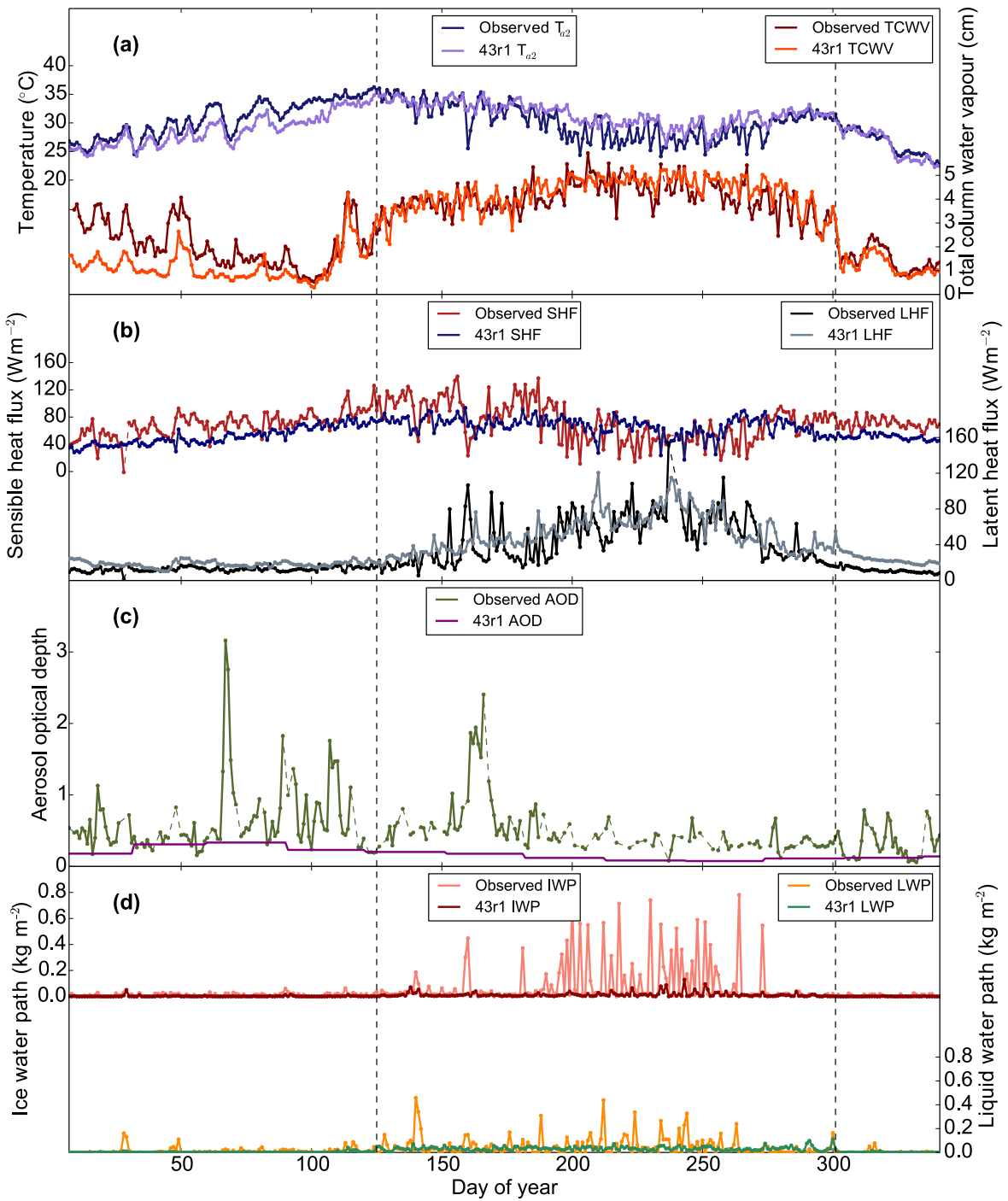

Figure 4. Observed and 43r1 non-radiative fluxes for Niamey during 2006. Plot (a) shows temperature and TCWV; (b) sensible and latent heat fluxes; (c) aerosol optical depth; and (d) ice water path and liquid water path. Dashed sections indicate imputed data, and dashed vertical lines indicate the beginning and end of the wet season.

\section{Results}

\subsection{Model radiative and non-radiative variables}

We begin with a comparison of observations to both $43 \mathrm{r} 1$ and ERA-I radiation fluxes at the surface and the TOA for long- and shortwave flux observations (Fig. A1). ERA-I has a coarser spatial resolution, with a horizontal grid of approximately $80 \mathrm{~km}$, and 60 vertical levels (Berrisford et al., 2011). ERA-I is also based on an IFS cycle $31 \mathrm{r} 2$, which was operational a decade earlier than 43r1. Numerous improvements to the physics and the dynamics of the model have been made in the intervening period, such as changes to the convection scheme leading to a much better capturing of the diurnal cycle of tropical convection (Bechtold et al., 2014). From
Fig. A1, we see that although there are some distinct changes between the two cycles of the model, most notably in ULR and to a lesser extent DLR (Fig. A1d and f), the behaviour of the two versions of the model tends to be more similar to each other than to the matched observations. Due to this similarity, we continue with comparisons of observations to 43r1 only but note that our general conclusions are applicable to ERA-I output. We explore reasons for the observation-model discrepancies in Sect. 4.2.

\subsubsection{Radiative variables}

For the shortwave fluxes, the model has a negative bias for RSR (Fig. 2a, d) and a positive model bias at the surface, with annual average biases of $-21 \mathrm{~W} \mathrm{~m}^{-2}$ in DSR (Fig. 2b, e) and 
$-13 \mathrm{~W} \mathrm{~m}^{-2}$ in USR (Fig. 2c, f). For all shortwave fluxes, the observations show large, day-to-day variations during the second part of the wet season (approximately days 200-300) which are not reproduced by the model.

For OLR, the model has a positive bias throughout the year (Fig. 3a, d). However, the majority of the model points lie within in the uncertainty bounds of the observations. In the wet season, when large day-to-day variability is seen in the observations but not in the model, differences can exceed the observational uncertainty. Here, the average daily bias is $-13 \mathrm{~W} \mathrm{~m}^{-2}$ (Table 2). In contrast, at the surface, there are larger biases in dry season longwave fluxes than in the wet season, with modelled DLR and ULR consistently underestimated (Fig. 3b, c, e, f). The correlation coefficients for both the dry seasons are high $\left(r^{2}=0.89\right.$ and 0.76 for ULR and DLR in the first dry season), suggesting that although the model has a significant negative bias, it captures the dry season variability of the surface longwave fluxes well. Wet season average bias in DLR and ULR is small at 0 and $1 \mathrm{~W} \mathrm{~m}^{-2}$, respectively, though this is due to cancellation of the model underestimation of DLR and ULR in the first part of the wet season (days 126-200) with the overestimation in the second part of the wet season (days 200-300). All radiative variables show more variability in the observations than in the model, reflecting the larger range of competing influences in comparison to the idealized and less chaotic model.

\subsubsection{Non-radiative variables}

Figure 4 presents observed and modelled $2 \mathrm{~m}$ air temperature, TCWV, LHF, SHF, aerosol optical depth (AOD) and IWP and LWP, with mean statistics shown in Table 3.

Air temperature at $2 \mathrm{~m}, T_{\mathrm{a} 2}$, is lower than, but closely coupled to, surface or skin temperature (Slingo et al., 2009) for which observations are not available at the study site. We find that observed and model $T_{\mathrm{a} 2}$ (Fig. 4a) follows a very similar pattern to ULR (Fig. 3b), as expected. In particular, we find the model generally underestimates observations during the dry season but with a high correlation coefficient $\left(r^{2}=0.89\right)$. During the wet season, as with ULR, the model values of $T_{\mathrm{a} 2}$ display less of the observed day-to-day variability. The seasonal cycle in TCWV is similar to that in $43 \mathrm{r} 1\left(r^{2}=0.80\right.$ for the whole year) but is much less variable than the observations during the wet season.

Figure $4 \mathrm{~b}$ shows modelled and observed THF. The model describes $66 \%$ of observed LHF variation over the year, with $43 \%$ of observed variation described in the wet season but only $10 \%$ of observed variation described in the dry season. In contrast, the model captures only $13 \%$ of the annual variation of SHF with the $52 \%$ of the observed variation in the first dry season but only $6 \%$ of the observed variation described during the wet season.

For $500 \mathrm{~nm}$ AOD from the AMF (Fig. 4c), we find large values ( $>3$ ) during the dry seasons and much less variability in the wet season. The model uses aerosol climatology (Dee
Table 2. Statistics from observation-43r1 comparison of radiative variables for the whole year (days 7-341), first dry season (days 7-125), wet season (days 126-301) and second dry season (days 302-341); Pearson's $r^{2}$ value (bold if significant to $p \leq 0.001$ ), the root mean square error and the bias are all defined in Sect. 3 .

\begin{tabular}{|c|c|c|c|c|c|}
\hline Variable & Statistic & $\begin{array}{r}\text { Whole } \\
\text { year }\end{array}$ & $\begin{array}{r}\text { First dry } \\
\text { season }\end{array}$ & $\begin{array}{r}\text { Wet } \\
\text { season }\end{array}$ & $\begin{array}{r}\text { Second dry } \\
\text { season }\end{array}$ \\
\hline \multirow{3}{*}{ OLR } & $r^{2}$ & 0.51 & 0.54 & 0.40 & 0.56 \\
\hline & $\operatorname{RMSE}\left(\mathrm{W} \mathrm{m}^{-2}\right)$ & 24 & 20 & 29 & 10 \\
\hline & bias $\left(\mathrm{W} \mathrm{m}^{-2}\right)$ & -12 & -12 & -13 & -5 \\
\hline \multirow{3}{*}{ DLR } & $r^{2}$ & 0.83 & 0.76 & 0.68 & 0.90 \\
\hline & $\operatorname{RMSE}\left(\mathrm{W} \mathrm{m}^{-2}\right)$ & 23 & 33 & 12 & 18 \\
\hline & bias $\left(\mathrm{W} \mathrm{m}^{-2}\right)$ & 13 & 29 & 0 & 16 \\
\hline \multirow{3}{*}{ ULR } & $r^{2}$ & 0.45 & 0.89 & 0.35 & 0.94 \\
\hline & $\operatorname{RMSE}\left(\mathrm{W} \mathrm{m}^{-2}\right)$ & 24 & 30 & 20 & 18 \\
\hline & bias $\left(\mathrm{W} \mathrm{m}^{-2}\right)$ & 12 & 28 & -1 & 17 \\
\hline \multirow{3}{*}{ RSR } & $r^{2}$ & 0.31 & 0.51 & 0.21 & 0.01 \\
\hline & $\operatorname{RMSE}\left(\mathrm{W} \mathrm{m}^{-2}\right)$ & 32 & 19 & 42 & 10 \\
\hline & bias $\left(\mathrm{W} \mathrm{m}^{-2}\right)$ & 18 & 13 & 24 & 8 \\
\hline \multirow{3}{*}{ DSR } & $r^{2}$ & 0.23 & 0.60 & 0.09 & 0.27 \\
\hline & $\operatorname{RMSE}\left(\mathrm{W} \mathrm{m}^{-2}\right)$ & 47 & 28 & 60 & 13 \\
\hline & bias $\left(\mathrm{W} \mathrm{m}^{-2}\right)$ & -21 & -13 & -30 & -3 \\
\hline \multirow{3}{*}{ USR } & $r^{2}$ & 0.43 & 0.64 & 0.14 & 0.33 \\
\hline & $\operatorname{RMSE}\left(\mathrm{W} \mathrm{m}^{-2}\right)$ & 17 & 12 & 21 & 5 \\
\hline & bias $\left(\mathrm{Wm}^{-2}\right)$ & -13 & -10 & -16 & -3 \\
\hline
\end{tabular}

et al., 2011), which bears little resemblance to the observations, and consistently underestimates the AOD throughout the year.

The model-observation IWP and LWP, though significant at the $p \leq 0.001$ level, capture only 13 and $8 \%$ of the observed variability, respectively (Fig. $4 \mathrm{~d}$ ). The model IWP and LWP have a consistent low bias with respect to the observations (Fig. 4), particularly during the wet season. Although there are significant correlations during the dry season $\left(r^{2}=0.39\right.$ and 0.08 , respectively) there are no significant correlations during the wet season when there are large variations in the observations.

Figure 5 shows that the model reproduces the observed large-scale seasonal pattern of RH of a very dry lower troposphere $(700-1000 \mathrm{hPa})$ during the dry season, with large variations and high $\mathrm{RH}$ throughout the troposphere during the wet season. The model has some consistent differences to the observations with a generally negative bias between 500 and $700 \mathrm{hPa}$ and a positive bias between 200 and $400 \mathrm{hPa}$ (Fig. 5c). 
Table 3. Statistics from observation-ERA-I comparison of non-radiative variables for the whole year (days 7-341), first dry season (days 7-125), wet season (days 126-301) and second dry season (days 302-341); Pearson's $r^{2}$ value (bold if significant to $p \leq 0.001$ ), the root mean square error and the bias are all defined in Sect. 3.

\begin{tabular}{|c|c|c|c|c|c|}
\hline Variable & Statistic & $\begin{array}{r}\text { Whole } \\
\text { year }\end{array}$ & $\begin{array}{r}\text { First dry } \\
\text { season }\end{array}$ & $\begin{array}{r}\text { Wet } \\
\text { season }\end{array}$ & $\begin{array}{r}\text { Second dry } \\
\text { season }\end{array}$ \\
\hline \multirow{3}{*}{ Temperature } & $r^{2}$ & 0.60 & 0.89 & 0.56 & 0.92 \\
\hline & $\operatorname{RMSE}\left({ }^{\circ} \mathrm{C}\right)$ & 2.1 & 2.1 & 2.2 & 0.9 \\
\hline & bias $\left({ }^{\circ} \mathrm{C}\right)$ & 0.0 & 1.8 & -1.3 & 0.3 \\
\hline \multirow{3}{*}{ TCWV } & $r^{2}$ & 0.80 & 0.52 & 0.74 & 0.94 \\
\hline & RMSE (cm) & 0.8 & 1.0 & 0.5 & 0.3 \\
\hline & bias $(\mathrm{cm})$ & 0.2 & 0.8 & -0.2 & 0.3 \\
\hline \multirow{3}{*}{ Latent heat flux } & $r^{2}$ & 0.66 & 0.10 & 0.43 & 0.36 \\
\hline & $\operatorname{RMSE}\left(\mathrm{W} \mathrm{m}^{-2}\right)$ & 17 & 7 & 22 & 11 \\
\hline & bias $\left(\mathrm{W} \mathrm{m}^{-2}\right)$ & -6 & -6 & -6 & -11 \\
\hline \multirow{3}{*}{ Sensible heat flux } & $r^{2}$ & 0.13 & 0.52 & 0.06 & 0.13 \\
\hline & $\operatorname{RMSE}\left(\mathrm{W} \mathrm{m}^{-2}\right)$ & 25 & 23 & 28 & 22 \\
\hline & bias $\left(\mathrm{W} \mathrm{m}^{-2}\right)$ & 11 & 18 & 5 & 20 \\
\hline \multirow{3}{*}{ Ice water path } & $r^{2}$ & 0.13 & 0.39 & 0.07 & 0.00 \\
\hline & $\operatorname{RMSE}\left(\mathrm{kg} \mathrm{m}^{-2}\right)$ & 0.13 & 0.02 & 0.18 & 0.01 \\
\hline & bias $\left(\mathrm{kg} \mathrm{m}^{-2}\right)$ & 0.05 & 0.01 & 0.08 & 0.01 \\
\hline \multirow{3}{*}{ Liquid water path } & $r^{2}$ & 0.08 & 0.12 & 0.01 & 0.08 \\
\hline & $\operatorname{RMSE}\left(\mathrm{kg} \mathrm{m}^{-2}\right)$ & 0.06 & 0.03 & 0.08 & 0.02 \\
\hline & bias $\left(\mathrm{kg} \mathrm{m}^{-2}\right)$ & 0.01 & 0.01 & 0.02 & 0.01 \\
\hline
\end{tabular}

\subsection{Surface radiative flux discrepancies}

We begin by examining the surface budget in both the model and the observations. Differences in up- and downwelling fluxes lead to differences in the surface energy budget (Fig. 6a), defined as the difference between the downwelling energy flux (net downward shortwave (DSR minus USR) plus DLR) and upwelling energy flux (ULR plus SHF plus LHF), using the convention that downwelling fluxes are positive. We find that the overestimation in model DLR and DSR outweighs the underestimation in ULR and USR, leading to a generally positive downwelling flux in the model, in contrast to the observed negative downwelling flux.

In the rest of this section, we take each of the surface fluxes in turn and examine the relationship between observed and model fluxes with respect to other variables, before using a multivariate model to interpret the observation-model discrepancy. Equations for all discrepancy linear models can be found in Appendix B.

\subsubsection{Surface downwelling shortwave radiation}

We remove the effect of the changing TOA TSI over the course of the year to emphasize the effect of the meteorological controls, though simply refer to this (DSR minus TSI) as DSR for the purposes of this section. We expect that the primary controls on the DSR reaching the surface will be scattering and absorption from aerosols, water vapour and clouds (Fig. 1). Therefore, we examine the DSR in both the observations and from 43r1 with relevant variables: AOD, LWP, IWP and TCWV. Table 4 presents statistics corresponding to surface shortwave fluxes.

As expected, the observational wet season variability in DSR is more closely correlated to variables related to clouds (TCWV, IWP and LWP), while AOD is more closely correlated to dry season variability. By combining IWP, TCWV and AOD, we generate a linear model (similar to that used by Miller et al., 2009) which explains $70 \%$ of the observed variability in DSR over the whole year (Fig. 7a). Figure 7b shows the contributions to the linear model, where negative values indicate that an increase in that variable corresponds 

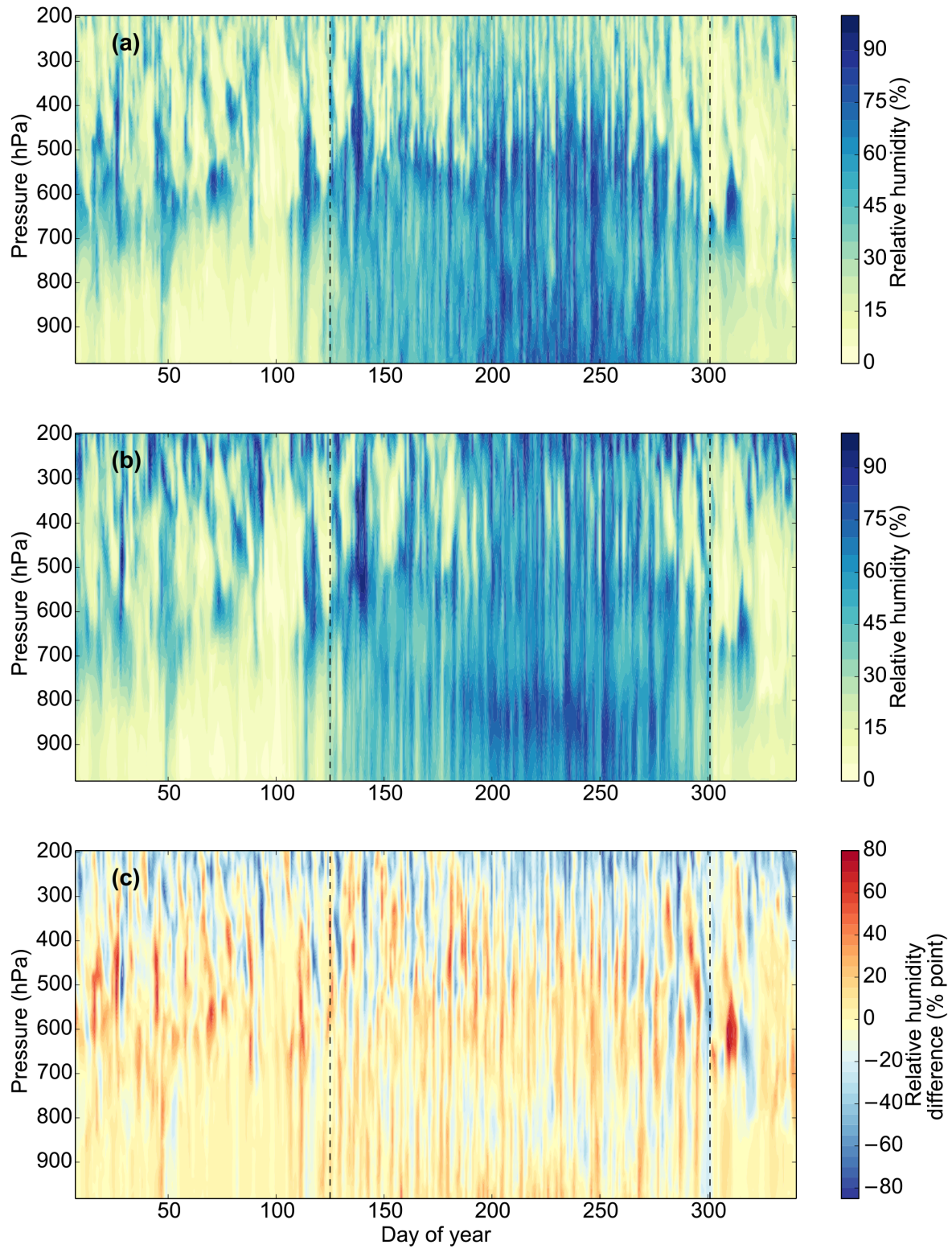

Figure 5. (a) Observed and (b) 43r1 daily mean of relative humidity profiles from 1000 to $200 \mathrm{hPa}$ above Niamey during 2006. Plot (c) is the observation-model relative humidity discrepancy.

to a decrease in DSR. We repeat this process with the corresponding model variables and find that TCWV and LWP have a higher correlation coefficient with DSR than in the observations, especially in the dry season which is most likely due to the poor representation of AOD variability. We generate a linear model using IWP and TCWV, a combination which gives high correlation coefficients throughout the year (Fig. 7c, d).

We perform linear regressions on the observation-model discrepancies in AOD, TCWV, IWP and LWP with the discrepancy in DSR. The discrepancy in IWP has a statistically significant correlation with that in DSR over the whole year but particularly in the wet season $\left(r^{2}=0.54\right)$. The correlation between the discrepancy in DSR and that in LWP is lower but still significant, while the discrepancy in TCWV has no significant correlation. The discrepancy in AOD has a significant correlation during the dry seasons $\left(r^{2}=0.27\right.$ and 0.54 , respectively). We combine the highest correlating discrepancies, IWP, AOD and LWP, in a linear model (Fig. 7e) which captures $56 \%$ of the variability in the observation-model discrepancy in DSR over the year. Figure $7 \mathrm{f}$ shows that during the dry season the contribution to the linear model from AOD is largest, while during the wet season IWP largely determines the variability in the DSR discrepancy. From this, we 

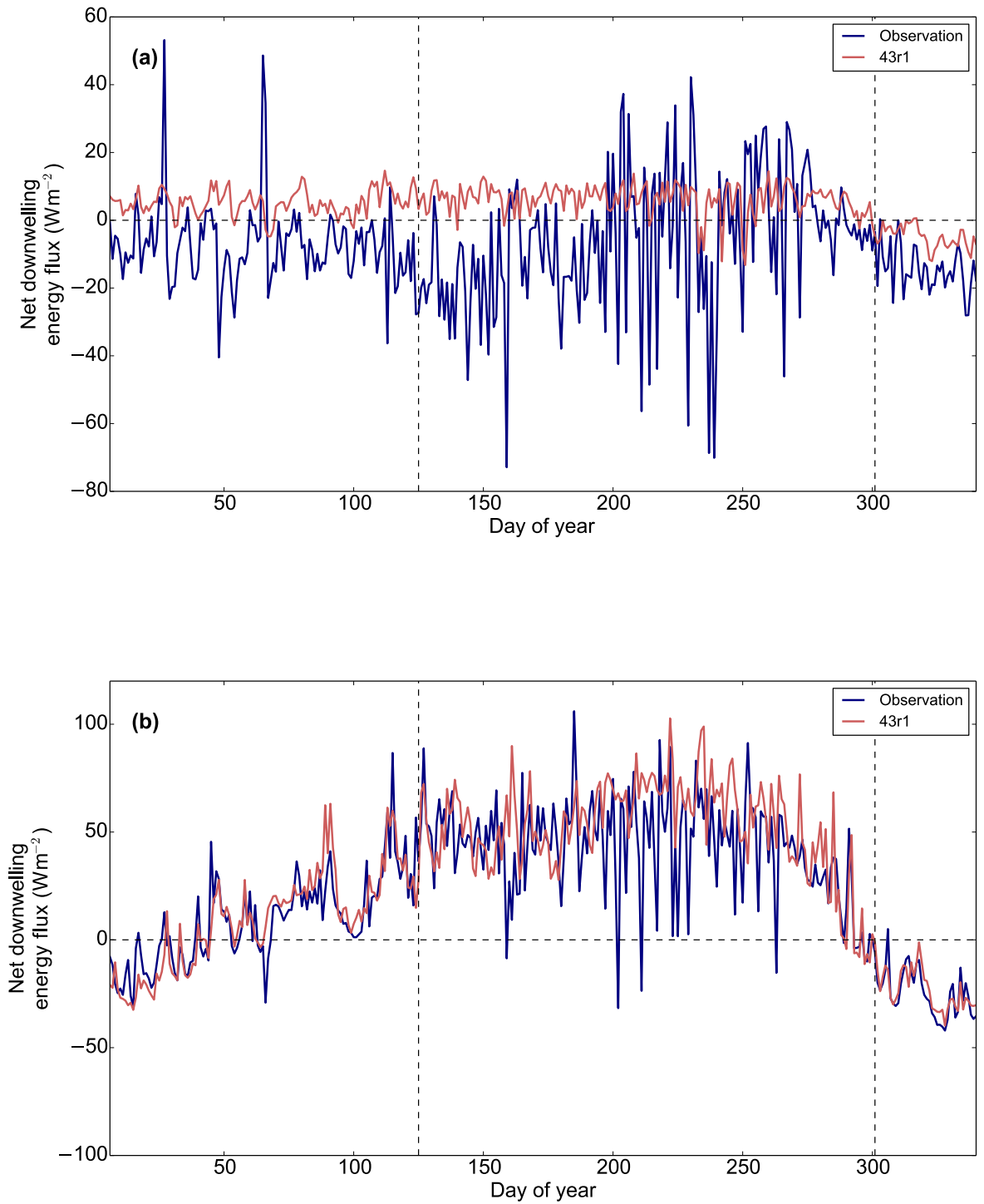

Figure 6. Surface and TOA energy budget at Niamey during 2006. Plot (a) shows the net energy flux at the surface (downwelling long- and shortwave surface radiation fluxes minus upwelling long- and shortwave radiation surface fluxes and turbulent heat fluxes) for observations (blue) and 43r1 (red). Plot (b) is the net flux at the TOA (total solar irradiance minus reflected shortwave and outgoing longwave radiation), also for observations and 43r1. Positive values for both indicate more downwelling than upwelling energy flux. Dashed vertical lines indicate the beginning and end of the wet season.

infer that model negative bias in cloud IWP explains a significant proportion of the overestimation of insolation reaching the surface. This is particularly prevalent during the wet season, with day-to-day variations in AOD accounting for dry season overestimation of DSR at the surface.

\subsubsection{Surface upwelling shortwave radiation}

We consider the two factors which we would expect to produce an error in the model USR: discrepancy in DSR and the incorrect characterization of surface albedo. To estimate the surface albedo in the model and the observations, we take the ratio of USR to DSR or the proportion of DSR which is reflected upwards (inferred surface albedo, $\alpha$ ). Figure $8 \mathrm{~b}$ shows that the model generally has a positive bias in $\alpha$, ranging from 0.22 to 0.29 , contrasting with observations, where $\alpha$ varies between 0.14 and 0.29 . The seasonal contrast is due to the semi-arid nature of the region: dry conditions during the dry seasons lead to a high albedo, but during the wet season green vegetation and higher soil moisture reduce the surface albedo. This is consistent with monthly values of the normalized difference vegetation index (NDVI; Fig. 8b) from NASA MODIS, which peaks during August/September, approximately corresponding to when there is a minimum in 
Table 4. Shortwave surface fluxes: $r^{2}$ values from correlations between observed and 43r1 USR and DSR, and their discrepancy, to other variables for the whole year (days 7-341), first dry season (days 7-125), wet season (days 126-301) and second dry season (days 302-341); statistically significant (to $p \leq 0.001$ ) values are in bold. Italics indicate which variables were used in the linear model.

\begin{tabular}{|c|c|c|c|c|c|c|}
\hline Radiative flux & & Variable & $\begin{array}{r}\text { Whole } \\
\text { year }\end{array}$ & $\begin{array}{r}\text { Dry } \\
\text { season } 1\end{array}$ & $\begin{array}{c}\text { Wet } \\
\text { season }\end{array}$ & $\begin{array}{r}\text { Dry } \\
\text { season } 2\end{array}$ \\
\hline \multirow{15}{*}{ DSR } & \multirow{5}{*}{ Observations } & $A O D$ & 0.03 & 0.19 & 0.02 & 0.67 \\
\hline & & $T C W V$ & 0.38 & 0.11 & 0.31 & 0.46 \\
\hline & & $I W P$ & 0.51 & 0.47 & 0.53 & 0.10 \\
\hline & & LWP & 0.28 & 0.31 & 0.22 & 0.23 \\
\hline & & Linear model & 0.70 & 0.43 & 0.66 & 0.77 \\
\hline & \multirow{5}{*}{$43 \mathrm{r} 1$} & AOD & 0.06 & 0.00 & 0.00 & 0.01 \\
\hline & & $T C W V$ & 0.51 & 0.64 & 0.32 & 0.75 \\
\hline & & $I W P$ & 0.61 & 0.22 & 0.66 & 0.08 \\
\hline & & LWP & 0.38 & 0.63 & 0.13 & 0.58 \\
\hline & & Linear model & 0.73 & 0.64 & 0.69 & 0.71 \\
\hline & \multirow{5}{*}{ Discrepancy } & $A O D$ & 0.04 & 0.27 & 0.02 & 0.54 \\
\hline & & TCWV & 0.00 & 0.01 & 0.02 & 0.09 \\
\hline & & $I W P$ & 0.51 & 0.33 & 0.54 & 0.13 \\
\hline & & $L W P$ & 0.14 & 0.15 & 0.14 & 0.17 \\
\hline & & Linear model & 0.56 & 0.41 & 0.56 & 0.63 \\
\hline \multirow{5}{*}{ USR } & Observations & DSR & 0.77 & 0.87 & 0.85 & 0.89 \\
\hline & $43 \mathrm{r} 1$ & DSR & 0.70 & 0.96 & 0.75 & 0.90 \\
\hline & \multirow{3}{*}{ Discrepancy } & $D S R$ & 0.82 & 0.74 & 0.85 & 0.92 \\
\hline & & Albedo & 0.48 & 0.22 & 0.46 & 0.53 \\
\hline & & Linear model & 0.97 & 0.99 & 0.98 & 0.99 \\
\hline
\end{tabular}

surface albedo. Care must be taken when comparing these values because we compare a model grid-average value with point measurements of DSR and USR, which is only valid if the point measurements are representative of the larger geographical area. This point is discussed further in Sect. 5 .

To quantify the impact of the model bias in $\alpha$ on USR, we calculate the model USR that is consistent with using observed $\alpha$ values. Figure 8a shows that this adjusted USR is much closer in magnitude and variability to the observed USR than the original model USR $\left(r^{2}=0.70\right)$, suggesting a major source of error for the model USR originates from the poor characterization of the surface albedo over this study site.

To determine whether the model bias in DSR or $\alpha$ has more of an impact on model USR, we build a linear model of the USR observation-model discrepancy. We use the discrepancy in $\alpha$ and in DSR as the predictor variables (Table 4) as both are highly correlated with the discrepancy in USR $\left(r^{2}=0.48\right.$ and 0.82 , respectively) but have a relatively low correlation with each other $\left(r^{2}=0.13\right)$. Table 4 and Fig. 8c show that the linear model performs extremely well $\left(r^{2}=\right.$ $0.97)$ over the whole year. Figure $8 \mathrm{~d}$ shows that the larger contribution comes from the discrepancy in $\alpha$, although the discrepancy in DSR is responsible for the large variations during the wet season. This suggests that increased surface reflectivity and overestimated DSR in the model combine to produce an overestimation in USR.

\subsubsection{Surface downwelling longwave radiation}

Following Miller et al. (2009), we use observed $T_{\mathrm{a} 2}$, TCWV and AOD to build a linear model that accounts for $88 \%$ of the observed variability in DLR (Table 5, Fig. 9a). A similar linear model but without AOD explains $99 \%$ of the 43r1 variability in DLR (Fig. 9c). Considering the full year, the linear model for $43 \mathrm{r} 1$ gives greater weight to the contribution from TCWV with respect to $T_{\mathrm{a} 2}$ than the observational linear 

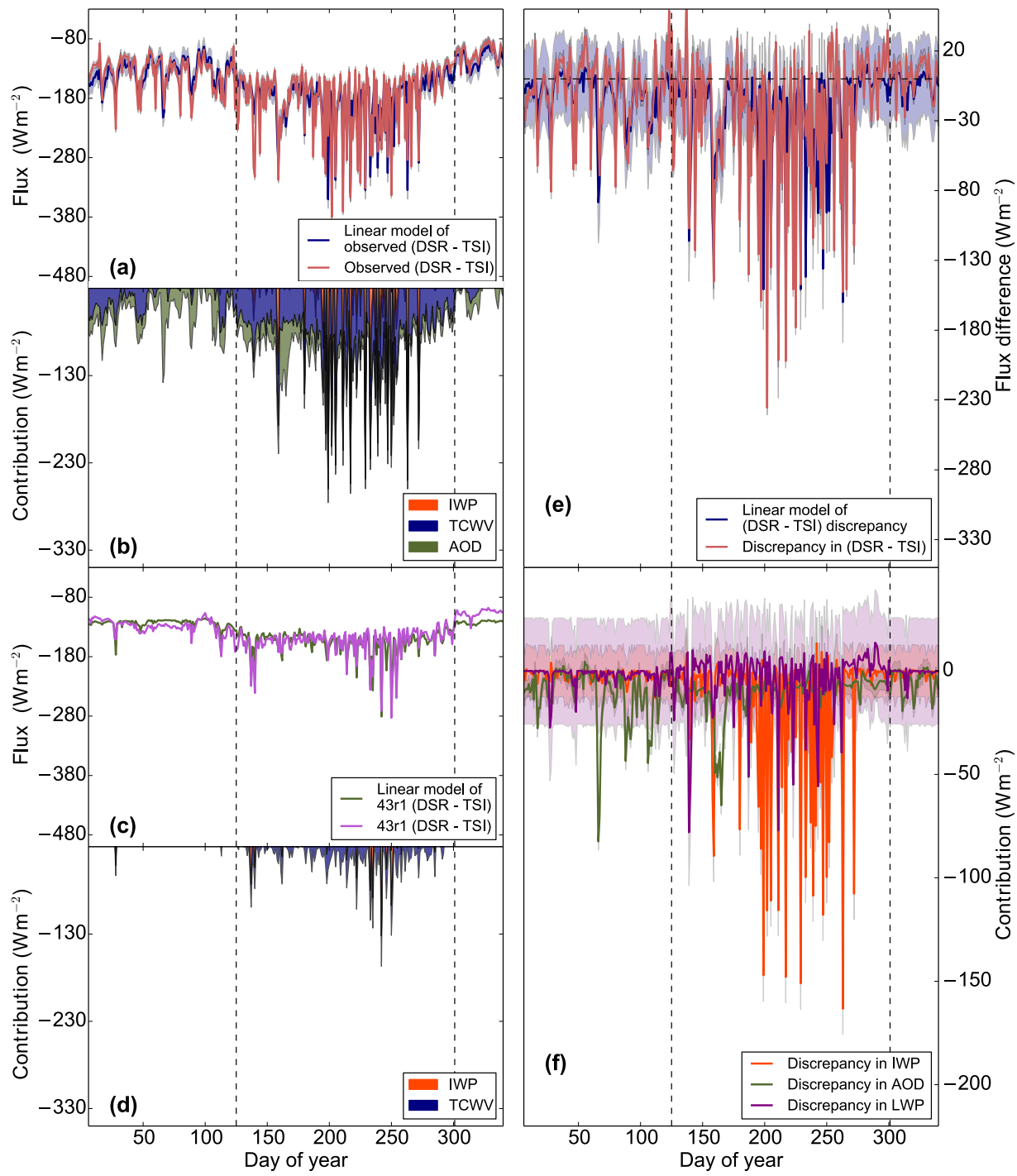

Figure 7. Downwelling shortwave radiation minus total solar irradiance (DSR-TSI), in observations and 43r1. Plot (a) shows DSR (blue) and the linear model (red) of (DSR-TSI) built from a linear combination of IWP (orange), TCWV (blue) and AOD (green) shown in plot (b). Plot (c) shows the 43r1 (DSR-TSI) (pink) and the linear model of 43r1 (DSR-TSI) (green) made up of IWP (orange) and TCWV (dark blue) in plot (d). Plot (e) shows the observation-43r1 discrepancy in red, with a linear model (blue) of this discrepancy built from discrepancies in IWP (green), aerosol optical depth (orange) and LWP (purple) in plot (f). Negative contributions in plots (b), (d) and (f) indicate that an increase in that variable corresponds to a decrease in DSR-TSI. Dashed lines indicate the beginning and end of the wet season.

model (compare Fig. 9b to d), a feature which is dominated by wet season behaviour.

The discrepancy in TCWV is found to have little correlation with the observation-model discrepancy in DLR and is therefore not used further. In contrast, the discrepancy in $T_{\mathrm{a} 2}$ has a stronger correlation with DLR discrepancy in the wet season $\left(r^{2}=0.46\right)$, while the discrepancy in AOD has a stronger correlation with DLR discrepancy in the first dry season $\left(r^{2}=0.45\right)$. We therefore build a linear model of the discrepancy in DLR with discrepancies from $T_{\mathrm{a} 2}$ and AOD (Fig. 9e). These two variables collectively account for $75 \%$ of the DLR discrepancy variability over the whole year, with higher correlations in the dry season than the wet season $\left(r^{2}=0.67\right.$ and 0.52 , respectively). Figure 9f shows that the discrepancy in DLR is largely driven by the discrepancies in $T_{\mathrm{a} 2}$, with peaks in AOD contributing to isolated events.

\subsubsection{Surface upwelling longwave radiation}

ULR is determined by variations in skin temperature, $T_{\mathrm{S}}$ and emissivity, $\epsilon$, through the Stefan-Boltzmann law:

$\mathrm{ULR}=\epsilon \sigma T_{\mathrm{s}}^{4}$,

where $\sigma$ denotes the Stefan-Boltzmann constant $\left(5.670 \times 10^{-8} \mathrm{~W} \mathrm{~m}^{-2} \mathrm{~K}^{-4}\right)$. ULR model error is there- 

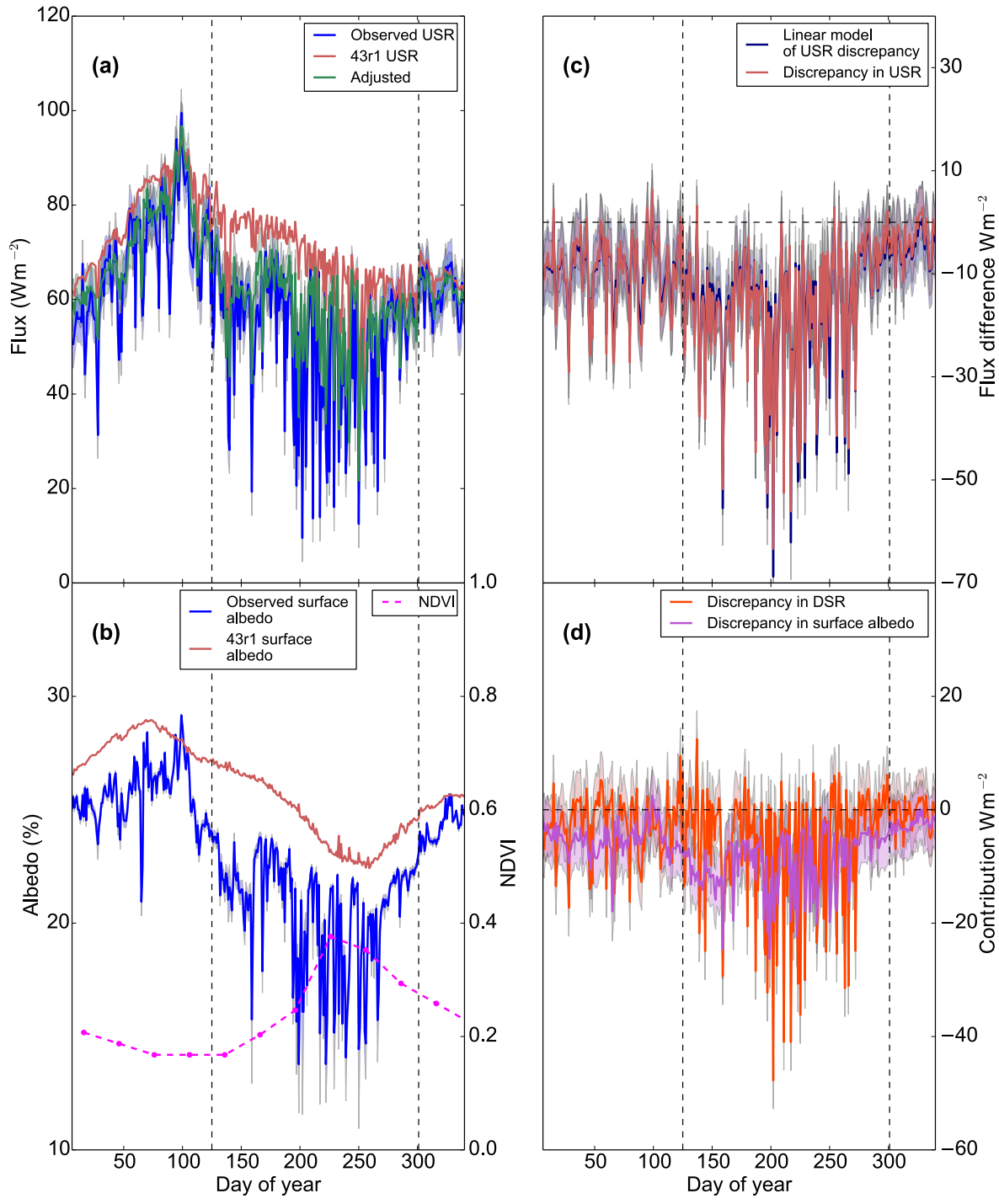

Figure 8. Plot (a) shows observed USR (blue), 43r1 USR (red) and "adjusted" USR (calculated from 43r1 DSR and observed surface albedo, green). Plot (b) shows inferred surface albedo as calculated by the ratio USR/DSR from the observations (blue) and 43r1 (red), as well as NDVI (see text). Plot (c) shows USR discrepancy (red) and linear model (blue) of USR discrepancy with contributions in plot (d) from discrepancy in surface albedo (pink) and DSR discrepancy (orange). Dashed lines indicate the beginning and end of the wet season.

fore likely to arise due to errors in either emissivity or in $T_{\mathrm{s}}$. We find that ULR and $T_{\mathrm{a} 2}$ (our proxy for $T_{\mathrm{s}}$ ) are highly correlated in both observations and 43r1 (Table 6), as expected. The observed minus model ULR discrepancy is also highly correlated to $T_{\mathrm{a} 2}$, suggesting that the errors in ULR are linked to those in $T_{\mathrm{s}}$. Possible sources of error in $T_{\mathrm{S}}$ include errors in surface heating, ground heat storage and the partitioning between ULR and the turbulent (latent and sensible) heat fluxes.

To explore the source of this temperature difference, we perform linear regressions of ULR first with absorbed shortwave radiation at the surface (net downward shortwave radiation flux or DSR minus USR) and then, with the addition DLR, of total downward radiation flux (net down- ward shortwave radiation flux plus DLR). The observed surface ULR is significantly correlated with observed net downward shortwave radiation flux through the year $\left(r^{2}=0.33\right)$. We find that this correlation is improved when we linearly regress observed ULR with the total downward radiation flux $\left(r^{2}=0.59\right)$, with the largest correlation during the dry season $\left(r^{2}=0.96\right)$. We find a similar result using $43 r 1$. The observation-model discrepancy in ULR is highly correlated to the discrepancy in total downward radiation flux. Although it is difficult to fully disentangle the cause and effect relationship between the upwelling and downwelling longwave radiation fluxes, the suggestion through this analysis is that the dry season discrepancy in $T_{\mathrm{S}}$ arises through an underesti- 
Table 5. Downwelling longwave surface fluxes: $r^{2}$ values from correlations between observed and 43r1 DLR, and their discrepancy, to other variables for the whole year (days 7-341), first dry season (days 7-125), wet season (days 126-301) and second dry season (days 302-341); statistically significant (to $p \leq 0.001$ ) values are in bold. Italics indicate which variables were used in the linear model.

\begin{tabular}{|c|c|c|c|c|c|c|}
\hline Radiative flux & & Variable & $\begin{array}{r}\text { Whole } \\
\text { year }\end{array}$ & $\begin{array}{r}\text { Dry } \\
\text { season } 1\end{array}$ & $\begin{array}{r}\text { Wet } \\
\text { season }\end{array}$ & $\begin{array}{r}\text { Dry } \\
\text { season } 2\end{array}$ \\
\hline \multirow{21}{*}{ DLR } & \multirow{7}{*}{ Observations } & $T C W V$ & 0.53 & 0.13 & 0.31 & 0.88 \\
\hline & & Temperature & 0.25 & 0.54 & 0.22 & 0.79 \\
\hline & & IWP & 0.04 & 0.26 & 0.00 & 0.02 \\
\hline & & LWP & 0.12 & 0.30 & 0.04 & 0.26 \\
\hline & & $A O D$ & 0.04 & 0.07 & 0.14 & 0.36 \\
\hline & & ULR & 0.28 & 0.61 & 0.19 & 0.79 \\
\hline & & Linear model & 0.88 & 0.82 & 0.81 & 0.96 \\
\hline & \multirow{7}{*}{$43 \mathrm{r} 1$} & $T C W V$ & 0.91 & 0.89 & 0.74 & 0.97 \\
\hline & & Temperature & 0.53 & 0.64 & 0.16 & 0.95 \\
\hline & & IWP & 0.18 & 0.15 & 0.07 & 0.12 \\
\hline & & LWP & 0.61 & 0.65 & 0.27 & 0.44 \\
\hline & & AOD & 0.31 & 0.14 & 0.16 & 0.08 \\
\hline & & ULR & 0.72 & 0.75 & 0.35 & 0.96 \\
\hline & & Linear model & 0.99 & 0.97 & 0.98 & 0.99 \\
\hline & \multirow{7}{*}{ Discrepancy } & TCWV & 0.32 & 0.00 & 0.17 & 0.01 \\
\hline & & Temperature & 0.65 & 0.30 & 0.46 & 0.15 \\
\hline & & IWP & 0.12 & 0.02 & 0.14 & 0.09 \\
\hline & & LWP & 0.21 & 0.45 & 0.07 & 0.18 \\
\hline & & ULR & 0.60 & 0.25 & 0.48 & 0.21 \\
\hline & & $A O D$ & 0.21 & 0.45 & 0.07 & 0.18 \\
\hline & & Linear model & 0.75 & 0.67 & 0.52 & 0.51 \\
\hline
\end{tabular}

mation in model DLR which is partially offset by an overestimation in net downward shortwave fluxes.

\subsection{TOA radiative flux discrepancies}

As with the surface budget, we examine the net radiation flux at the TOA (incoming solar - (OLR + RSR)) in both the model and observations (Fig. 6b). We find that despite large discrepancies in the RSR and OLR (Figs. 2 and 3) there is good agreement between the model and observed TOA budget, especially in the dry season. This is likely due to the RSR underestimation counteracting the OLR overestimation. The exception to this is the second part of the wet season, where the model does not capture the large variations seen in the observations. We now interpret OLR and RSR to establish which processes control observed and model variations, and their discrepancies.

\subsubsection{TOA reflected shortwave radiation}

We find that the shortwave component of the TOA budget has similar controls to DSR (Table 7) with significant correlations between observed RSR and cloud products (IWP and LWP, $r^{2}=0.56$ and 0.31 , respectively). Control from IWP is strongest in the wet season, while the highest correlation with LWP and AOD is during the first dry season. Using LWP, IWP and AOD, we build a linear model which explains $73 \%$ of the observed RSR variability over the course of the year, with the highest correlation during the wet season (Fig. 10a). IWP and LWP have the largest contribution during the wet season, with AOD contributing more in the dry seasons (Fig. 10b). Repeating the procedure with 43r1 shows very similar dependencies of $43 \mathrm{r} 1 \mathrm{RSR}$ on LWP and IWP, suggesting that the response to the cloud forcing is sim- 

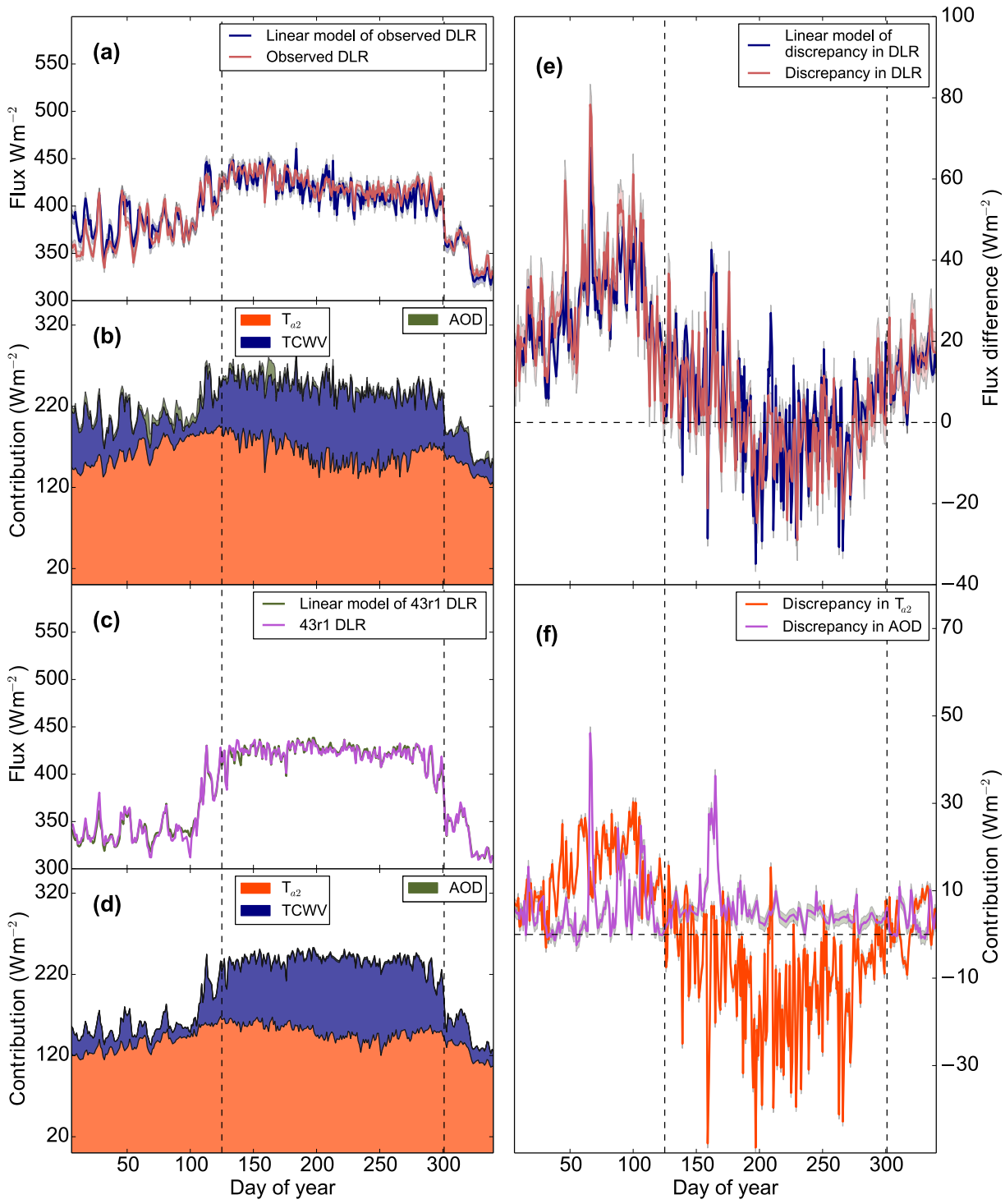

Figure 9. The same as Fig. 7 but for downwelling longwave radiation, with observation-43r1 linear model contributions from TCWV (blue), $2 \mathrm{~m}$ air temperature (orange) and AOD (green) in plots (b) and (d), and discrepancy model contributions from $2 \mathrm{~m}$ air temperature (orange) and AOD (pink) in plot (f).

ilar. Using the 43r1 IWP and LWP in a linear model, we can recreate $74 \%$ of the variability in 43r1 RSR (Fig. 10c).

Discrepancies in RSR and the predictor variables show that, as with DSR, the largest correlation with RSR discrepancy is that in IWP, followed by that in LWP (Table 7). This suggests that the underlying discrepancies in RSR have the same cause as those in DSR, namely the underestimation of IWP and LWP, especially in the wet season. Indeed, we see a very strong correlation between DSR and RSR both in the observations and 43r1 individually, as well as a high correlation between the observation-model discrepancy in DSR and RSR. By combining the discrepancies in IWP, LWP and AOD, we build a linear model which explains $55 \%$ of the variability in the discrepancy of RSR over the course of the year (Table 7). Comparison of the discrepancy models for both RSR (Fig. 10e and f) and DSR (Fig. 7e and f) shows that the RSR discrepancy model is less dependent on AOD but also includes a dependency on LWP.

\subsubsection{TOA outgoing longwave radiation}

We finish our examination of the radiation fluxes with the OLR. There is a significant correlation between observed OLR and TCWV, IWP and LWP, with the strongest correlation between IWP/LWP and OLR during the dry season, and TCWV having a similar correlation in both the first dry and wet seasons. Upper tropospheric humidity (UTH) has a statistically significant, albeit lower, correlation during the wet 
Table 6. Upwelling longwave surface fluxes: $r^{2}$ values from correlations between observed and 43r1 ULR, and their discrepancy, to other variables for the whole year (days 7-341), first dry season (days 7-125), wet season (days 126-301) and second dry season (days 302-341); statistically significant (to $p \leq 0.001$ ) values are in bold. Italics indicate which variables were used in the linear model.

\begin{tabular}{|c|c|c|c|c|c|c|}
\hline Radiative flux & & Variable & $\begin{array}{r}\text { Whole } \\
\text { year }\end{array}$ & $\begin{array}{r}\text { Dry } \\
\text { season } 1\end{array}$ & $\begin{array}{r}\text { Wet } \\
\text { season }\end{array}$ & $\begin{array}{r}\text { Dry } \\
\text { season } 2\end{array}$ \\
\hline \multirow{9}{*}{ ULR } & \multirow{3}{*}{ Observations } & Temperature & 0.92 & 0.95 & 0.90 & 0.97 \\
\hline & & Net SW & 0.33 & 0.46 & 0.33 & 0.04 \\
\hline & & Net SW + DLR & 0.59 & 0.92 & 0.49 & 0.96 \\
\hline & \multirow{3}{*}{$43 \mathrm{r} 1$} & Temperature & 0.93 & 0.97 & 0.88 & 0.99 \\
\hline & & Net SW & 0.28 & 0.39 & 0.11 & 0.10 \\
\hline & & Net SW + DLR & $\mathbf{0 . 8 2}$ & 0.98 & 0.40 & 0.98 \\
\hline & \multirow{3}{*}{ Discrepancy } & Temperature & 0.87 & 0.73 & 0.80 & 0.73 \\
\hline & & Net SW & 0.33 & 0.08 & 0.47 & 0.15 \\
\hline & & Net SW + DLR & 0.70 & 0.51 & 0.64 & 0.66 \\
\hline
\end{tabular}

Table 7. TOA RSR fluxes: $r^{2}$ values from correlations between observed and 43r1 RSR, and their discrepancy, to other variables for the whole year (days 7-341), first dry season (days 7-125), wet season (days 126-301) and second dry season (days 302-341); statistically significant (to $p \leq 0.001$ ) values are in bold. Italics indicate which variables were used in the linear model.

\begin{tabular}{|c|c|c|c|c|c|c|}
\hline Radiative flux & & Variable & $\begin{array}{r}\text { Whole } \\
\text { year }\end{array}$ & $\begin{array}{r}\text { Dry } \\
\text { season } 1\end{array}$ & $\begin{array}{r}\text { Wet } \\
\text { season }\end{array}$ & $\begin{array}{r}\text { Dry } \\
\text { season } 2\end{array}$ \\
\hline \multirow{15}{*}{ RSR } & \multirow{5}{*}{ Observations } & $I W P$ & 0.56 & 0.49 & 0.58 & 0.24 \\
\hline & & $L W P$ & 0.31 & 0.37 & 0.24 & 0.13 \\
\hline & & $A O D$ & 0.01 & 0.17 & 0.01 & 0.29 \\
\hline & & DSR & 0.62 & 0.21 & 0.83 & 0.67 \\
\hline & & Linear model & 0.73 & 0.56 & 0.73 & 0.43 \\
\hline & \multirow{5}{*}{$43 \mathrm{r} 1$} & $I W P$ & 0.70 & 0.33 & 0.69 & 0.01 \\
\hline & & $L W P$ & 0.24 & 0.57 & 0.07 & 0.37 \\
\hline & & AOD & 0.11 & 0.07 & 0.01 & 0.00 \\
\hline & & DSR & 0.32 & 0.10 & 0.77 & 0.35 \\
\hline & & Linear model & 0.74 & 0.51 & 0.71 & 0.23 \\
\hline & \multirow{5}{*}{ Discrepancy } & $I W P$ & 0.43 & 0.20 & 0.44 & 0.07 \\
\hline & & $L W P$ & 0.16 & 0.23 & 0.15 & 0.12 \\
\hline & & $A O D$ & 0.05 & 0.13 & 0.03 & 0.01 \\
\hline & & DSR & 0.80 & 0.51 & 0.85 & 0.39 \\
\hline & & Linear model & 0.55 & 0.33 & 0.55 & 0.07 \\
\hline
\end{tabular}

season $\left(r^{2}=0.13\right)$. ULR, which we might expect to influence OLR under clear-sky conditions, does not have a significant correlation during the dry season, though it does during the wet season. By combining IWP, LWP and TCWV, we build a linear model which explains $60 \%$ of the observed variability throughout the year (Table 8, Fig. 11a). Much of the seasonal cycle in this linear model is driven by TCWV, while the day-to-day variability during the wet season comes from variations in IWP and LWP (Fig. 11b). Again, these contributions are shown as negatives in the contributions' 

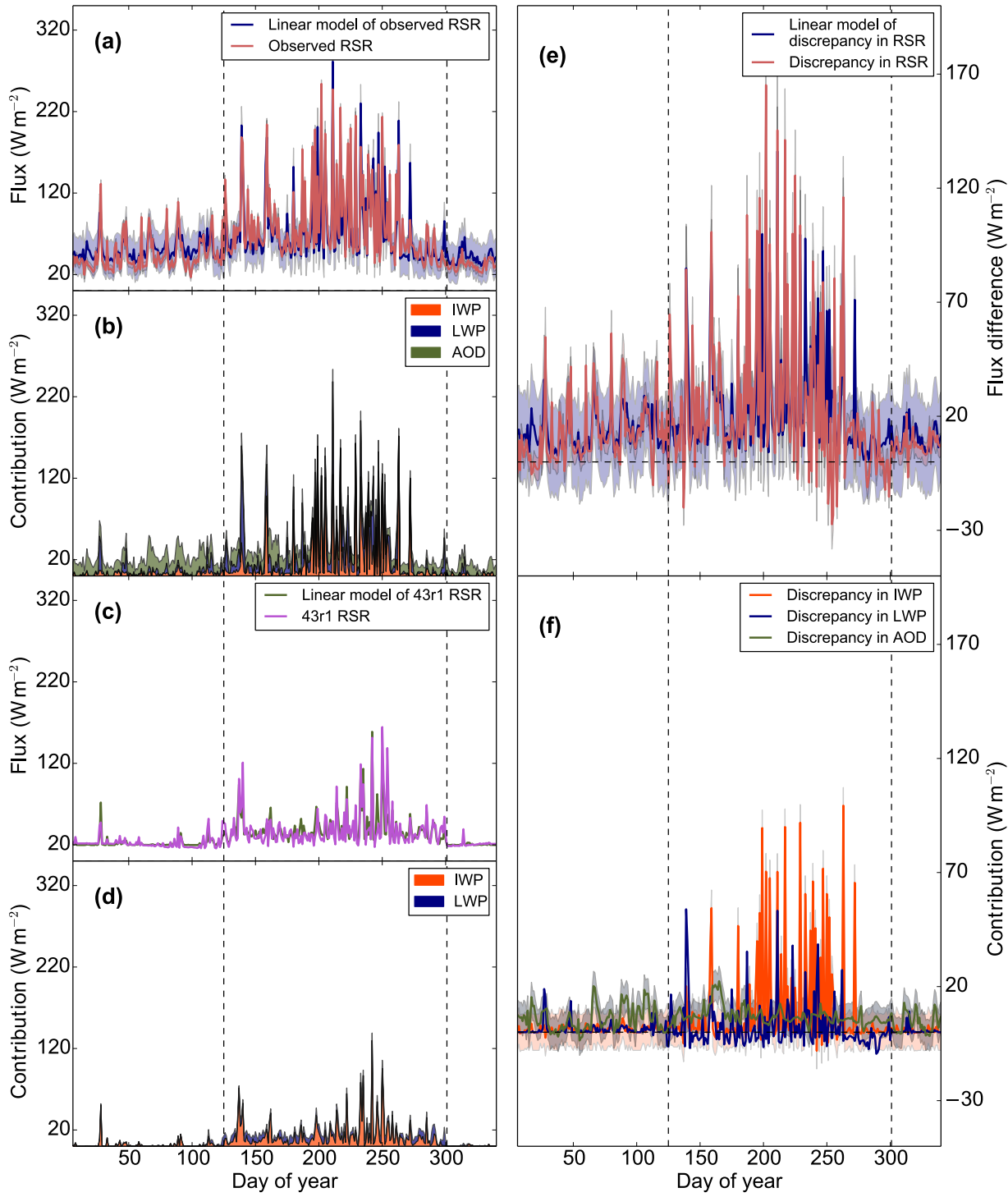

Figure 10. The same as Fig. 7 but for reflected shortwave radiation at the TOA, with observation-43r1 linear model contributions from IWP (orange), LWP (blue) and (observations only) AOD (green) in plots (b) and (d), and discrepancy model contributions from IWP (orange), LWP (blue) and AOD (green) in plot (f).

plot, as an increase in these variables leads to a decrease in OLR.

We see a similar pattern with 43r1, though LWP has a lower correlation with OLR during the year $\left(r^{2}=0.20\right)$ and no significant correlation in any individual seasons. Instead, IWP has a stronger correlation $\left(r^{2}=0.69\right)$, and UTH has a higher correlation than the observations $\left(r^{2}=0.54\right.$ rising to 0.87 during the wet season). The linear model from TCWV, IWP and UTH (Fig. 11c) captures most of the variability in 43r1 OLR $\left(r^{2}=0.85\right)$, though TCWV contributes less to the linear model than in the observations (Fig. 11d).

As noted above, for the majority of the days examined, 43r1 OLR falls within the uncertainty bounds of the observations, with the exception of the wet season. We therefore re- strict our discrepancy model to just this period. There is little correlation between the discrepancy in wet season IWP, ULR or UTH and the discrepancy in OLR, and no significant correlation with TCWV or LWP (Table 8). We therefore build a linear model of the discrepancy in wet season OLR using the discrepancy in IWP, ULR and UTH, producing a model with correlation coefficient of $r^{2}=0.36$ (Fig. 11). From the contributions to this model (Fig. 11), we see that the largest contribution to this model is from the discrepancy in UTH, with minor contributions from IWP and LWP, suggesting that model humidity profiles are the largest cause of OLR discrepancies. 
Table 8. TOA OLR fluxes: $r^{2}$ values from correlations between observed and 43r1 OLR, and their discrepancy, to other variables for the whole year (days 7-341), first dry season (days 7-125), wet season (days 126-301) and second dry season (days 302-341); statistically significant (to $p \leq 0.001$ ) values are in bold. Italics indicate which variables were used in the linear model.

\begin{tabular}{|c|c|c|c|c|c|c|}
\hline Radiative flux & & Variable & $\begin{array}{r}\text { Whole } \\
\text { year }\end{array}$ & $\begin{array}{r}\text { Dry } \\
\text { season } 1\end{array}$ & $\begin{array}{r}\text { Wet } \\
\text { season }\end{array}$ & $\begin{array}{r}\text { Dry } \\
\text { season } 2\end{array}$ \\
\hline \multirow{18}{*}{ OLR } & \multirow{6}{*}{ Observations } & $T C W V$ & 0.43 & $\mathbf{0 . 3 3}$ & 0.35 & 0.10 \\
\hline & & $I W P$ & 0.34 & 0.40 & 0.38 & 0.39 \\
\hline & & $L W P$ & 0.23 & 0.34 & 0.17 & 0.03 \\
\hline & & ULR & 0.07 & 0.01 & 0.26 & 0.00 \\
\hline & & UTH & 0.13 & 0.07 & 0.14 & 0.03 \\
\hline & & Linear model & 0.60 & 0.47 & 0.58 & 0.13 \\
\hline & \multirow{6}{*}{$43 \mathrm{r} 1$} & $T C W V$ & 0.40 & 0.13 & 0.36 & 0.13 \\
\hline & & $I W P$ & 0.69 & 0.39 & 0.72 & 0.52 \\
\hline & & LWP & 0.20 & 0.07 & 0.04 & 0.03 \\
\hline & & ULR & 0.02 & 0.01 & 0.08 & 0.05 \\
\hline & & $U T H$ & 0.54 & 0.40 & 0.64 & 0.23 \\
\hline & & Linear model & 0.85 & 0.60 & 0.87 & 0.43 \\
\hline & \multirow{6}{*}{ Discrepancy } & TCWV & & & 0.03 & \\
\hline & & $I W P$ & & & 0.15 & \\
\hline & & LWP & & & 0.02 & \\
\hline & & $U L R$ & & & 0.14 & \\
\hline & & UTH & & & 0.10 & \\
\hline & & Linear model & & & 0.35 & \\
\hline
\end{tabular}

\section{Discussion and concluding remarks}

The purpose of this study has been to characterize differences in TOA and surface radiation fluxes between ECMWF's IFS 43r1 and observations from GERB/SEVIRI; to link these discrepancies to differences in physical processes; and to examine links between surface and TOA discrepancies. We do this using some simple statistics and by extending the methods of multivariate linear models used by Miller et al. (2009).

We are able to link observation-model discrepancies in physical processes to those in radiation fluxes. The most striking of these impacts arises from a lack of ice clouds, manifested as an underestimation in the ice water path, which causes large wet season discrepancies in shortwave radiation. This lack of ice clouds leads to too much shortwave radiation reaching the surface and not enough being reflected at the TOA. This effect is exacerbated by the use of an aerosol loading climatology which typically underestimates the real amount of aerosol present in the atmosphere over Niamey and is the major source of the model overestimation of surface DSR in the dry season. This agrees with an assessment of an earlier cycle of the IFS, 32r3, used for a reanalysis by Agustí-Panareda et al. (2010), though here we directly link the lack of cloud and aerosol loading to an overestimation of DSR. Marsham et al. (2015), in their study of controls of surface and TOA radiation budgets in a similar site in Algeria (Bordj Badji Mokhtar at $21.4^{\circ} \mathrm{N}, 0.9^{\circ} \mathrm{E}$ ), also find that net shortwave radiation at the surface is controlled by a balance of clouds, AOD and TCWV, consistent with our results here. The positive bias in model DSR leads to an overestimation of net shortwave absorption by the surface and overestimation of USR. However, we find that for RSR at the TOA, the largest contribution to the observation-model discrepancy remains the underestimated cloud ice water path.

Turning to the longwave regime, we find that the model bias in ice water path also contributes to a positive bias in wet season OLR, though discrepancies in upper tropospheric humidity and ULR also play a role. Our analysis suggests that the discrepancy in ULR is itself due to an underestimation of skin temperature. The origin of this discrepancy in skin temperature is difficult to identify: we find that the model generally shows a positive surface energy budget (where down- 

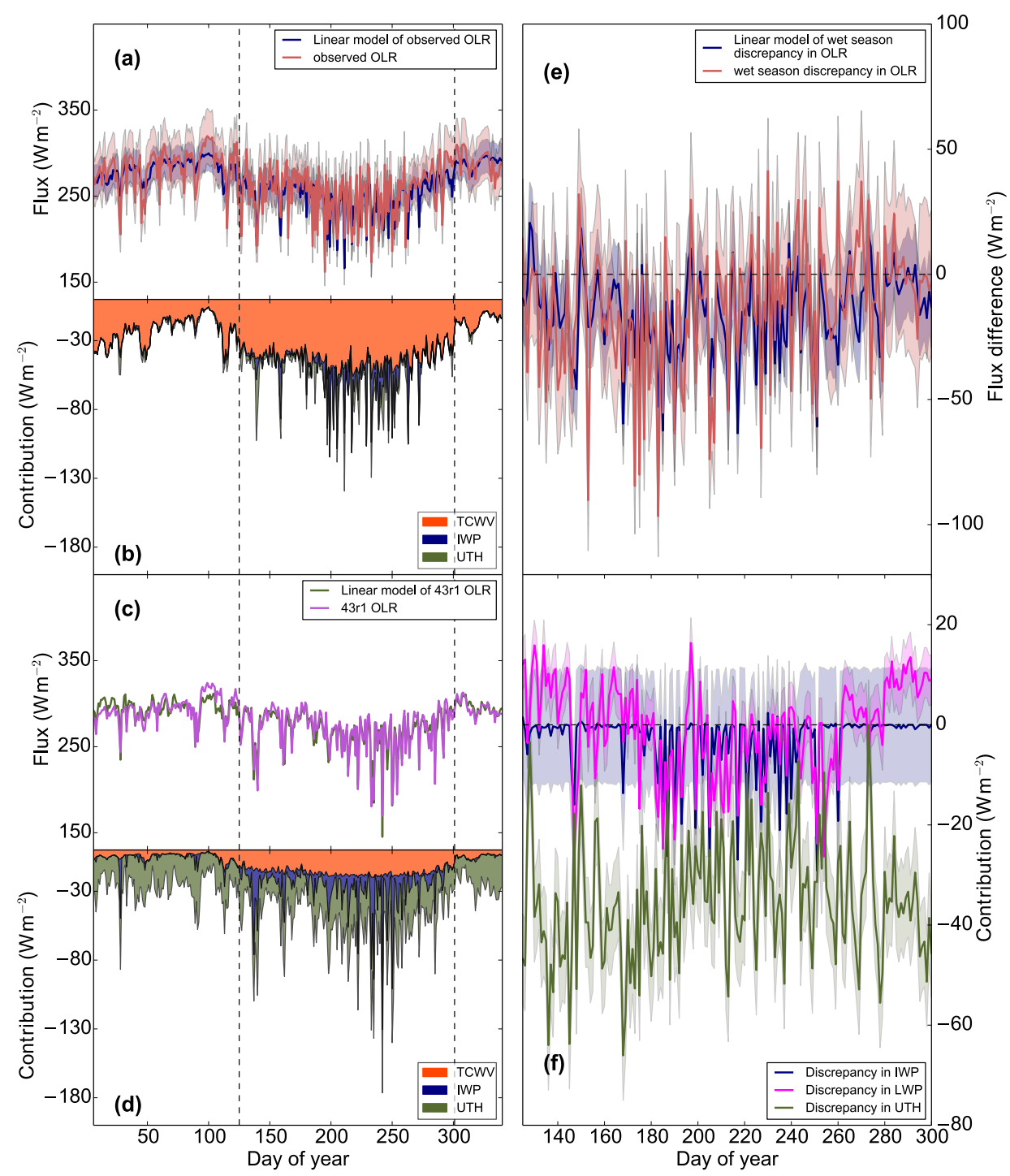

Figure 11. The same as Fig. 7 but for outgoing longwave radiation at the TOA, with observation-43r1 linear model contributions from TCWV (orange), IWP (blue) and UTH (green) in plots (b) and (d), and discrepancy model contributions from IWP (blue) and UTH (green) and LWP (pink) in plot (f). Negative contributions in plots (b), (d) and (f) indicate that an increase in that variable corresponds to a decrease in OLR.

welling is the positive direction), while the observations suggest the surface energy budget is generally negative. This would logically result in an enhanced skin temperature in the model and an overestimation of ULR. The higher correlation of ULR with a combination of net DSR and DLR at the surface may indicate complex feedbacks. A cooler nearsurface temperature profile in the model could lead to lower DLR, which would in turn lead to lower longwave absorption at the surface and therefore a lower skin temperature. Clearly, separating the cause and effect of the underestimated skin temperature is difficult. However, this temperature discrepancy, regardless of origin, can be directly linked to the discrepancy in DLR, particularly in the wet season. Marked peaks in model-observation DLR discrepancies result from significant aerosol events which are not captured in the model aerosol climatology.

There are limitations to the approach we have taken here. A significant caveat relates to the comparison of point measurements with area averages. However, assuming a nonstatic atmosphere, the use of daily averages rather than instantaneous measurements from the surface (point site), satellite $(\sim 10 \mathrm{~km}$ resolution) and model $(\sim 29 \mathrm{~km}$ resolution) should, to some degree, account for the mismatch in spatial scales given the higher native temporal resolution of the surface ( $1 \mathrm{~s}$ ) and satellite observations (15 $\mathrm{min})$. The qualitative agreement in the temporal variability in NDVI from MODIS $(\sim 110 \mathrm{~km})$ and the surface albedo derived from the ARM site gives confidence in the general representa- 
tiveness of the site in terms of surface properties. We also use the upper bounds of instrumental uncertainty to avoid over-interpreting model-observation discrepancies which lie within the bounds of measurement error.

The method we have used here does rely heavily on the availability of high-frequency measurements of radiative and meteorological variables from surface sites, which are not widely available. However, we find that larger-scale satellite products, such as ice and liquid water path, have been integral to our analysis of TOA fluxes in particular, suggesting this method could potentially be extended to larger spatial scales using suitably validated satellite products.

In summary, we have shown in this study that the use of multivariate linear models can give us deeper insight into how physical processes in 43r1 impact the evolution of radiative fluxes at the surface and the TOA in Niamey, as well as identify where shortcomings exist in the current version of the model.
Data availability. We acknowledge a number of organizations for provision of data. Data were obtained from the Atmospheric Radiation Measurement (ARM) climate research facility, a US Department of Energy Office of Science User Facility sponsored by the Office of Biological and Environmental Research. Data used are qcrad1longM1.s2 (https://doi.org/10.5439/1227214); nimmetM1.s2 (https://doi.org/10.5439/1025220); (https://doi.org/10.5439/1021460); nimsondewnpnM1.b1 (https://doi.org/10.5439/1097546) and nim30qcecorM1.b1 (https///doi.org/10.5439/1169504). Data were also obtained from CMSAF (Schulz et al., 2009), which are copyright (2017), EUMETSAT (https://doi.org/10.5676/EUM_SAF_CM/CLAAS/V002). GERB HR data were made available by the Royal Meteorological Institute of Belgium (RMIB). NDVI data were obtained from NASA Earth Observations (https://doi.org/10.5067/MODIS/MOD13C2.006). ECMWF IFS 43r1 output were made available by Robin Hogan, ECMWF. 


\section{Appendix A: ERA-I-43r1 comparison}

Figure showing ERA-Interim and IFS cycle 43r1 differences, as discussed in Sect. 4.
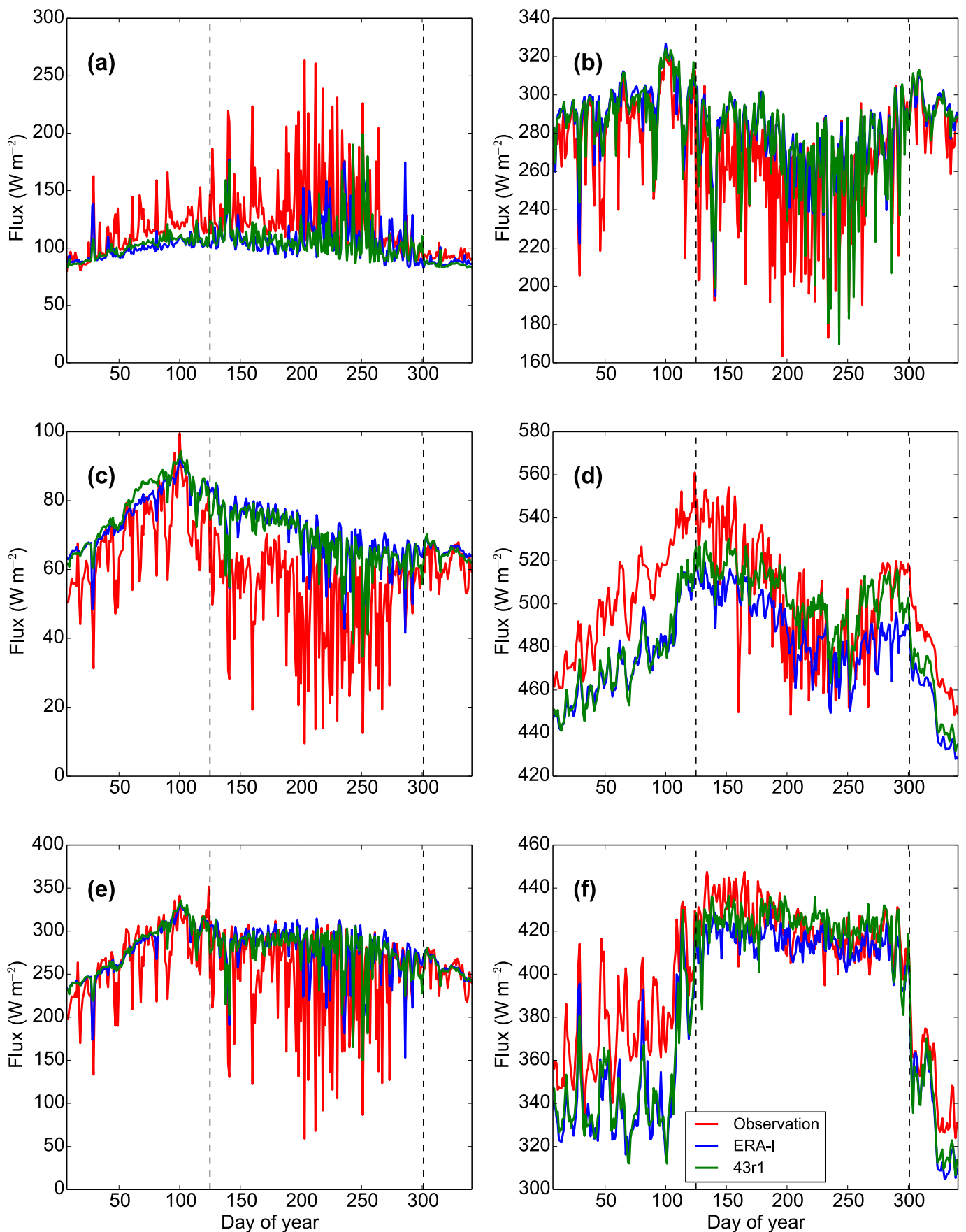

Figure A1. Comparison between observations (red), ERA-Interim (blue) and 43r1 (green) for (a) TOA reflected shortwave; (b) TOA outgoing longwave; (c) surface upwelling shortwave; (d) upwelling longwave; (e) downwelling shortwave; and (f) downwelling longwave radiation fluxes. Dashed lines indicate the beginning and end of the wet season. 


\section{Appendix B: Linear model equations}

The equations for the linear models used in Sect. 4.2, where primes indicate observation-model discrepancies.

\section{Surface downwelling shortwave radiation:}

$\mathrm{DSR}^{\prime} \mathrm{W} \mathrm{m}^{-2}=(3 \pm 2) \mathrm{W} \mathrm{m}^{-2}+(-209 \pm 12) \mathrm{W} \mathrm{kg}^{-2}$

$$
\begin{aligned}
& \times \mathrm{IWP}^{\prime} \mathrm{kg} \mathrm{m}^{-2}+(-29 \pm 4) \mathrm{W} \mathrm{m}^{-2} \times \mathrm{AOD}^{\prime} \\
& +(-181 \pm 25) \mathrm{W} \mathrm{kg}^{-2} \times \mathrm{LWP}^{\prime} \mathrm{kg} \mathrm{m}^{-2}
\end{aligned}
$$

Surface upwelling shortwave radiation:

$$
\begin{aligned}
\mathrm{USR}^{\prime} \mathrm{Wm}^{-2} & =(-1.5 \pm 1.8) \mathrm{Wm}^{-2}+(0.201 \pm 0.003) \\
& \times \mathrm{DSR}^{\prime} \mathrm{W} \mathrm{m}^{-2}+(229 \pm 5) \mathrm{Wm}^{-2} \times \alpha^{\prime}
\end{aligned}
$$

Surface downwelling longwave radiation:

$$
\begin{aligned}
\mathrm{DLR}^{\prime} \mathrm{W} \mathrm{m}^{-2} & =(7.2 \pm 0.7) \mathrm{W} \mathrm{m}^{-2} \\
& +(7.3 \pm 0.2) \mathrm{W} \mathrm{m}^{-2} \mathrm{~K}^{-1} \times T^{\prime} \mathrm{K} \\
& +(16.3 \pm 1.4) \mathrm{W} \mathrm{m}^{-2} \times \mathrm{AOD}^{\prime}
\end{aligned}
$$

TOA reflected shortwave radiation:

$$
\begin{aligned}
\mathrm{RSR}^{\prime} \mathrm{W} \mathrm{m}^{-2} & =(5 \pm 2) \mathrm{W} \mathrm{m}^{-2}+(127 \pm 8) \mathrm{W} \mathrm{kg}^{-2} \\
& \times \mathrm{IWP}^{\prime} \mathrm{kg} \mathrm{m}^{-2}+(125 \pm 16) \mathrm{W} \mathrm{kg}^{-2} \\
& \times \mathrm{LWP}^{\prime} \mathrm{kg} \mathrm{m}^{-2}+(30 \pm 7) \mathrm{W} \mathrm{m}^{-2} \\
& \times \mathrm{AOD}^{\prime}
\end{aligned}
$$

TOA outgoing longwave radiation:

$$
\begin{aligned}
\mathrm{OLR}^{\prime} \mathrm{W} \mathrm{m}^{-2} & =(23 \pm 5) \mathrm{W} \mathrm{kg}^{-2}+(-37 \pm 11) \mathrm{Wkg}^{-2} \\
& \times \mathrm{IWP}^{\prime} \mathrm{kg} \mathrm{m}^{-2}+(0.5 \pm 0.1) \times \mathrm{ULR}^{\prime} \mathrm{W} \mathrm{kg}^{-2} \\
& +(-66 \pm 9) \mathrm{W} \mathrm{kg}^{-2} \times \mathrm{UTH}^{\prime}
\end{aligned}
$$


Competing interests. The authors declare that they have no conflict of interest.

Acknowledgements. Paul I. Palmer acknowledges his Royal Society Wolfson Research Merit Award and funding from the NERC National Centre for Earth Observaton. Anna Mackie was supported by the UK Natural Environment Research Council (grant NE/L002558/1) through the University of Edinburgh's E3 Doctoral Training Partnership. Additionally, the authors would like to thank Robin Hogan at ECMWF for the 43r1 output and help with interpreting it, and Ronald L. Miller for his helpful advice on the use of multivariate linear models.

Edited by: Stelios Kazadzis

Reviewed by: two anonymous referees

\section{References}

Agustí-Panareda, A., Beljaars, A., Ahlgrimm, M., Balsamo, G., Bock, O., Forbes, R., Ghelli, A., Guichard, F., Köhler, M., Meynadier, R., and Morcrette, J. J.: The ECMWF re-analysis for the AMMA observational campaign, Q. J. Roy. Meteor. Soc., 136, 1457-1472, https://doi.org/10.1002/qj.662, 2010.

Ansell, C., Brindley, H. E., Pradhan, Y., and Saunders, R.: Mineral dust aerosol net direct radiative effect during GERBILS field campaign period derived from SEVIRI and GERB, J. Geophys. Res.-Atmos., 119, 4070-4086, https://doi.org/10.1002/2013JD020681, 2014.

Bechtold, P., Semane, N., Lopez, P., Chaboureau, J.-P., Beljaars, A., and Bormann, N.: Representing Equilibrium and Nonequilibrium Convection in Large-Scale Models, J. Atmos. Sci., 71, 734-753, https://doi.org/10.1175/JAS-D-13-0163.1, 2014.

Berrisford, P., Dee, D., Poli, P., Brugge, R., Fielding, K., Fuentes, M., Kållberg, P., Kobayashi, S., Uppala, S., and Simmons, A.: The ERA-Interim archive Version 2.0, Shinfield Park, Reading, 2011.

Brindley, H. E.: Estimating the top-of-atmosphere longwave radiative forcing due to Saharan dust from satellite observations over a west African surface site, Atmos. Sci. Lett., 8, 74-79, https://doi.org/10.1002/asl.155, 2007.

Brindley, H. E. and Bantges, R. J.: The Spectral Signature of Recent Climate Change, Current Climate Change Reports, 2, 112-126, https://doi.org/10.1007/s40641-016-0039-5, 2016.

Dee, D. P., Uppala, S. M., Simmons, A. J., Berrisford, P., Poli, P., Kobayashi, S., Andrae, U., Balmaseda, M. A., Balsamo, G., Bauer, P., Bechtold, P., Beljaars, A. C. M., van de Berg, L., Bidlot, J., Bormann, N., Delsol, C., Dragani, R., Fuentes, M., Geer, A. J., Haimberger, L., Healy, S. B., Hersbach, H., Hólm, E. V., Isaksen, L., Kållberg, P., Köhler, M., Matricardi, M., Mcnally, A. P., Monge-Sanz, B. M., Morcrette, J. J., Park, B. K., Peubey, C., de Rosnay, P., Tavolato, C., Thépaut, J. N., and Vitart, F.: The ERA-Interim reanalysis: Configuration and performance of the data assimilation system, Q. J. Roy. Meteor. Soc., 137, 553-597, https://doi.org/10.1002/qj.828, 2011.

Dewitte, S., Gonzalez, L., Clerbaux, N., Ipe, A., Bertrand, C., and De Paepe, B.: The Geostationary Earth Radiation Budget Edition
1 data processing algorithms, Adv. Space Res., 41, 1906-1913, https://doi.org/10.1016/j.asr.2007.07.042, 2008.

Dolinar, E. K., Dong, X., Xi, B., Jiang, J. H., and Su, H.: Evaluation of CMIP5 simulated clouds and TOA radiation budgets using NASA satellite observations, Clim. Dynam., 44, 2229-2247, https://doi.org/10.1007/s00382-014-2158-9, 2015.

Finkensieper, S., Meirink, J-F., van Zadelhoff, G-J., Hanschmann, T., Benas, N., Stengel, M., Fuchs, P., Hollmann, R. and Werscheck, M.: CLAAS-2: CM SAF CLoud property dAtAset using SEVIRI - Edition 2, Satellite Application Facility on Climate Monitoring, 2016.

Flato, G., Marotzke, J., Abiodun, B., Braconnot, P., Chou, S., Collins, W., Cox, P., Driouech, F., Emori, S., Eyring, V., Forest, C., Gleckler, P., Guilyardi, E., Jakob, C., Kattsov, V., Reason, C., and Rummukainen, M.: Evaluation of Climate Models, Climate Change 2013: The Physical Science Basis. Contribution of Working Group I to the Fifth Assessment Report of the Intergovernmental Panel on Climate Change, 741-866, https://doi.org/10.1017/CBO9781107415324, 2013.

Harries, J. E., Russell, J. E., Hanafin, J. A., Brindley, H., Futyan, J., Rufus, J., Kellock, S., Matthews, G., Wrigley, R., Last, A., Mueller, J., Mossavati, R., Ashmall, J., Sawyer, E., Parker, D., Caldwell, M., Allan, P. M., Smith, A., Bates, M. J., Coan, B., Stewart, B. C., Lepine, D. R., Cornwall, L. A., Corney, D. R., Ricketts, M. J., Drummond, D., Smart, D., Cutler, R., Dewitte, S., Clerbaux, N., Gonzalez, L., Ipe, A., Bertrand, C., Joukoff, A., Crommelynck, D., Nelms, N., Llewellyn-Jones, D. T., Butcher, G., Smith, G. L., Szewczyk, Z. P., Mlynczak, P. E., Slingo, A., Allan, R. P., and Ringer, M. A.: The Geostationary Earth Radiation Budget Project, B. Am. Meteorol. Soc., 86, 945-960, https://doi.org/10.1175/BAMS-86-7-945, 2005.

Harrison, L., Michalsky, J., and Berndt, J.: Automated multifilter rotating shadow-band radiometer: an instrument for optical depth and radiation measurements, Appl. Optics, 33, 5118-5125, https://doi.org/10.1364/AO.33.005118, 1994.

Hartmann, D. J., Klein Tank, A. M. G., Rusticucci, M., Alexander, L. V., Brönnimann, S., Charabi, Y. A.-R., Dentener, F. J., Dlugokencky, E. J., Easterling, D. R., Kaplan, A., Soden, B. J., Thorne, P. W., Wild, M., and Zhai, P.: Observations: Atmosphere and Surface, Climate Change 2013: The Physical Science Basis. Contribution of Working Group I to the Fifth Assessment Report of the Intergovernmental Panel on Climate Change, 159254, https://doi.org/10.1017/CBO9781107415324.008, 2013.

Hasternath, S. and Lamb, P.: Some aspects of the circulation and climate over the eastern equatorial Atlantic, Mon. Weather Rev., 105, 1019-1023, https://doi.org/10.1175/15200493(1977)105<1019:SAOCAC>2.0.CO;2, 1977.

Hogan, R. J. and Bozzo, A.: Mitigating errors in surface temperature forecasts using approximate radiation updates, J. Adv. Model. Earth Sy., 7, 836-853, https://doi.org/10.1002/2015MS000455, 2015.

Johnson, B. T., Osborne, S. R., Haywood, J. M., and Harrison, M. A. J.: Aircraft measurements of biomass burning aerosol over West Africa during DABEX, J. Geophys. Res.-Atmos., 113, 115, https://doi.org/10.1029/2007JD009451, 2008.

Lélé, M. and Lamb, P. J.: Variability of the Intertropical Front (ITF) and Rainfall over the West African Sudan-Sahel Zone, J. Climate, 23, 3984-4004, https://doi.org/10.1175/2010JCLI3277.1, 2010. 
Loeb, N. G., Kato, S., Su, W., Wong, T., Rose, F. G., Doelling, D. R., Norris, J. R., and Huang, X.: Advances in Understanding Top-ofAtmosphere Radiation Variability from Satellite Observations, Surv. Geophys., 33, 359-385, https://doi.org/10.1007/s10712012-9175-1, 2012.

Marsham, J. H., Parker, D. J., Todd, M. C., Banks, J. R., Brindley, H. E., Garcia-Carreras, L., Roberts, A. J., and Ryder, C. L.: The contrasting roles of water and dust in controlling daily variations in radiative heating of the summertime Saharan heat low, Atmos. Chem. Phys., 16, 3563-3575, https://doi.org/10.5194/acp16-3563-2016, 2016.

McFarlane, S. A., Mather, J. H., and Ackerman, T. P.: Analysis of tropical radiative heating profiles: A comparison of models and observations, J. Geophys. Res., 112, 1-22, https://doi.org/10.1029/2006JD008290, 2007.

McFarlane, S. A., Kassianov, E. I., Barnard, J., Flynn, C., and Ackerman, T. P.: Surface shortwave aerosol radiative forcing during the Atmospheric Radiation Measurement Mobile Facility deployment in Niamey, Niger, J. Geophys. Res.-Atmos., 114, 1-17, https://doi.org/10.1029/2008JD010491, 2009.

Michalsky, J. J., Schlemmer, J. A., Berkheiser, W. E., Berndt, J. L., Harrison, L. C., Laulainen, N. S., Larson, N. R., and Barnard, J. C.: Multiyear measurements of aerosol optical depth in the Atmospheric Radiation Measurement and Quantitative Links programs, J. Geophys. Res.-Atmos., 106, 12099-12107, https://doi.org/10.1029/2001JD900096, 2001.

Miller, M. A., Ghate, V. P., and Zahn, R. K.: The radiation budget of the West African Sahel and its controls: A perspective from observations and global climate models, J. Climate, 25, 59765996, https://doi.org/10.1175/JCLI-D-11-00072.1, 2012.

Miller, M. J. and Slingo, A.: The arm mobile facility and its first international deployment - Measuring radiative flux divergence in west Africa, B. Am. Meteorol. Soc., 88, 1229-1244, https://doi.org/10.1175/BAMS-88-8-1229, 2007.

Miller, R. L., Slingo, A., Barnard, J. C., and Kassianov, E.: Seasonal contrast in the surface energy balance of the Sahel, J. Geophys. Res.-Atmos., 114, 1-19, https://doi.org/10.1029/2008JD010521, 2009.

Milton, S. F., Greed, G., Brooks, M. E., Haywood, J., Johnson, B., Allan, R. P., Slingo, A., and Grey, W. M. F.: Modeled and observed atmospheric radiation balance during the West African dry season: Role of mineral dust, biomass burning aerosol, and surface albedo, J. Geophys. Res.-Atmos., 113, 124, https://doi.org/10.1029/2007JD009741, 2008.

Ohmura, A., Dutton, E. G., Forgan, B., Fröhlich, C., Gilgen, H., Hegner, H., Heimo, A., König-Langlo, G., McArthur, B., Müller, G., Philipona, R., Pinker, R., Whitlock, C. H., Dehne, K., and Wild, M.: Baseline Surface Radiation Network (BSRN/WCRP): New Precision Radiometry for Climate Research, B. Am. Meteorol. Soc. 79, 2115-2136, https://doi.org/10.1175/15200477(1998)079<2115:BSRNBW>2.0.CO;2, 1998.

Schmetz, J., Pili, P., Tjemkes, S., Just, D., Kerkmann, J., Rota, S., and Ratier, A.: Supplement to An Introduction to Meteosat Second Generation (MSG), B. Am. Meteorol. Soc., 83, 991-991, https://doi.org/10.1175/BAMS-83-7-Schmetz-1, 2002.
Schulz, J., Albert, P., Behr, H.-D., Caprion, D., Deneke, H., Dewitte, S., Dürr, B., Fuchs, P., Gratzki, A., Hechler, P., Hollmann, R., Johnston, S., Karlsson, K.-G., Manninen, T., Müller, R., Reuter, M., Riihelä, A., Roebeling, R., Selbach, N., Tetzlaff, A., Thomas, W., Werscheck, M., Wolters, E., and Zelenka, A.: Operational climate monitoring from space: the EUMETSAT Satellite Application Facility on Climate Monitoring (CM-SAF), Atmos. Chem. Phys., 9, 1687-1709, https://doi.org/10.5194/acp-9-1687-2009, 2009.

Settle, J. J., Bharmal, N. A., Robinson, G. J., and Slingo, A.: Sampling uncertainties in surface radiation budget calculations in RADAGAST, J. Geophys. Res.-Atmos., 113, D00E02, https://doi.org/10.1029/2008JD010509, 2008.

Slingo, A., Ackerman, T. P., Allan, R. P., Kassianov, E. I., McFarlane, S. A., Robinson, G. J., Barnard, J. C., Miller, M. A., Harries, J. E., Russell, J. E., and Dewitte, S.: Observations of the impact of a major Saharan dust storm on the atmospheric radiation balance, Geophys. Res. Lett., 33, L24817, https://doi.org/10.1029/2006GL027869, 2006.

Slingo, A., Bharmal, N. A., Robinson, G. J., Settle, J. J., Allan, R. P., White, H. E., Lamb, P. J., Lélé, M. I., Turner, D. D., McFarlane, S., Kassianov, E., Barnard, J., Flynn, C., and Miller, M.: Overview of observations from the RADAGAST experiment in Niamey, Niger: Meteorology and thermodynamic variables, J. Geophys. Res.-Atmos., 114, 1-19, https://doi.org/10.1029/2008JD009909, 2008.

Slingo, A., Bharmal, N. A., Robinson, G. J., Settle, J. J., Allan, R. P., White, H. E., Lamb, P. J., Lélé, M. I., Turner, D. D., McFarlane, S., Kassianov, E., Barnard, J., Flynn, C., and Miller, M.: Overview of observations from the RADAGAST experiment in Niamey, Niger: Meteorology and thermodynamic variables, J. Geophys. Res.-Atmos., 114, 1-19, https://doi.org/10.1029/2008JD009909, 2009.

Tegen, I., Hollrig, P., Chin, M., Fung, I., Jacob, D., and Penner, J.: Contribution of different aerosol species to the global aerosol extinction optical thickness: Estimates from model results, J. Geophys. Res.-Atmos., 102, 23895-23915, https://doi.org/10.1029/97JD01864, 1997.

Walsh, J. E., Chapman, W. L., and Portis, D. H.: Arctic Cloud Fraction and Radiative Fluxes in Atmospheric Reanalyses, J. Climate, 22, 2316-2334, https://doi.org/10.1175/2008JCLI2213.1, 2009.

Wielicki, B. A., Wong, T., Allan, R. P., Slingo, A., Kiehl, J. T., Soden, B. J., Gordon, C. T., Miller, A. J., Yang, S.-K., Randall, D. A., Robertson, F., Susskind, J., and Jacobowitz, H.: Evidence for large decadal variability in the tropical mean radiative energy budget, Science, 295, 841-844, https://doi.org/10.1126/science.1065837, 2002.

Wild, M.: Global dimming and brightening: A review, J. Geophys. Res., 114, D00D16, https://doi.org/10.1029/2008JD011470, 2009.

Wilks, D. S.: Statistical Methods in the Atmospheric Sciences, Academic Press, Oxford, 3rd Edn., 2011. 